\title{
Experimental Characterization of the Near-Wall Plasma in a 6-kW Hall Thruster and Comparison to Simulation
}

\author{
Rohit Shastry ${ }^{1}$ and Alec D. Gallimore ${ }^{2}$ \\ Plasmadynamics and Electric Propulsion Laboratory, The University of Michigan, Ann Arbor, MI, 48109 \\ and \\ Richard R. Hofer ${ }^{3}$ \\ Jet Propulsion Laboratory, California Institute of Technology, Pasadena, CA, 91109
}

\begin{abstract}
In order to better understand interactions between the plasma and channel walls of a Hall thruster, the near-wall plasma was characterized within the H6 Hall thruster using five flush-mounted Langmuir probes. These probes were placed within the last $15 \%$ of the discharge channel and were used to measure plasma potential, electron temperature, and ion number density near the inner and outer channel walls. These data were then compared to prior internal measurements inside the channel using a High-speed Axial Reciprocating Probe stage. Comparison of these data has shown that, at the nominal operating condition of $300 \mathrm{~V}$ and $20 \mathrm{mg} / \mathrm{s}$ anode flow rate, the plasma near the wall begins to accelerate further upstream than plasma closer to centerline. This shift in acceleration zone creates large radial electric fields $(\sim 40-50 \mathrm{~V} / \mathrm{mm})$ that tend to defocus ions and drive them towards the walls. The shift is likely caused by large plasma density gradients between centerline and the channel walls, creating a significant deviation of equipotentials from magnetic field lines near the walls. Electron temperature axial profiles were found to be largely consistent across the channel, supporting the isothermal assumption along magnetic field lines. The experimental results were also compared to simulation results from the hybrid-PIC program HPHall-2. General agreement was found between simulation and experiment for axial profiles of plasma potential, electron temperature, and ion number density, with minor differences occurring in peak locations. Slight asymmetries in properties were found between the inner and outer channel walls despite the use of a symmetric magnetic field topology. This asymmetry was caused by a difference in the location of the maximum radial magnetic field, resulting in axial shifts of acceleration zone and peak electron temperature. This result is supported by asymmetric erosion profiles after 334 hours of operation, showing increased erosion along the outer wall where acceleration began further upstream.
\end{abstract}

\section{Nomenclature}

$\begin{array}{ll}A_{p} & =\text { probe area } \\ A_{s} & =\text { sheath area } \\ D_{T, m} & =\text { mean thruster diameter } \\ e & =\text { elementary charge } \\ j_{i, s a t} & =\text { ion saturation current density } \\ M_{i} & =\text { ion mass }\end{array}$

\footnotetext{
${ }^{1}$ Presently a Research Electrical Engineer, NASA Glenn Research Center, 21000 Brookpark Rd., MS 301-3, Cleveland, OH 44135, rohit.shastry@ nasa.gov, AIAA member.

2 Arthur F. Thurnau Professor of Aerospace Engineering, Director of Plasmadynamics and Electric Propulsion Laboratory, The University of Michigan, 1320 Beal Ave., Ann Arbor, MI 48105, alec.gallimore@umich.edu, AIAA Associate Fellow. .

${ }^{3}$ Senior Engineer, Electric Propulsion Group, 4800 Oak Grove Dr., MS 125-109, Pasadena, CA 91109, richard.r.hofer@jpl.nasa.gov, AIAA senior member.
} 


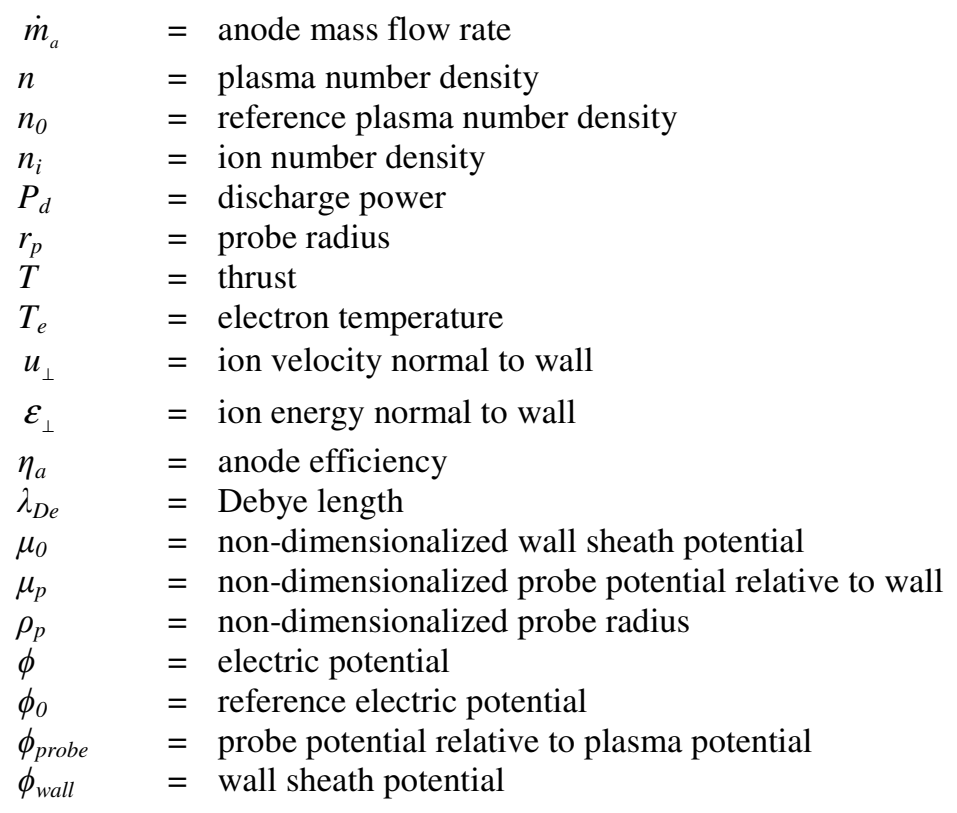

\section{Introduction}

$\mathrm{H}$ ALL thruster lifetime models currently in development aim to provide predictive tools that would eliminate or substantially reduce the need to perform long-duration, expensive life tests of flight articles [1-5]. A critical part of these modeling efforts is the need to understand and characterize the interaction between the plasma and the discharge channel walls. This interaction is composed of several complex processes that are not fully understood, and yet significantly affect thruster performance and lifetime. Several notable advances have been made in recent years in understanding plasma-wall interactions in Hall thrusters [6-8], but there is presently a noticeable lack of experimental validation. In particular, measurements of various plasma properties along the ceramic walls and comparison to those in the bulk plasma would greatly contribute to the understanding of Hall thruster wall physics, as well as provide validation and/or allow refinement of existing models [9-12].

Due to the extreme environment of the plasma, obtaining measurements within the channel can be challenging due to the low survivability of probes. This can be mitigated by reciprocating the probe on a high-speed stage [1315], or circumvented entirely by interrogating the plasma using laser-induced fluorescence (LIF) [16-18]. Both methods have been used extensively with a high degree of success. However, these techniques are limited in their ability to interrogate the near-wall region; probe reciprocation can only get within a few millimeters of the wall due to the physical size of the probe, and LIF, while capable of higher wall proximity than probe reciprocation, is unable to easily obtain plasma densities and currents. For these reasons, flush-mounted wall probes are an attractive choice for this investigation, and have been successfully used to interrogate the near-wall region of Hall thrusters [9-12,1921].

In order to characterize the near-wall plasma of a Hall thruster, five flush-mounted Langmuir probes were placed within each erosion ring of the H6 Hall thruster. These probes were placed within the last $15 \%$ of the channel, where the acceleration zone, region of high electron temperatures, and region of significant erosion were expected to occur. At each location, the plasma potential, electron temperature, and ion number density of the near-wall plasma were measured. These values were then compared to prior measurements taken by Reid [15] closer to channel centerline. The data were also compared to simulation results obtained using the hybrid-PIC code HPHall-2.

The paper is organized as follow: Section II will describe the vacuum facility, H6 Hall thruster, and the mechanical and electrical setup of the Langmuir probes used in this study. Section III then compares axial profiles of plasma potential, electron temperature, and ion number density at various radial locations within the discharge channel. Section IV discusses the implications of the results described in Section III, as well as compares the experimental results to computational results obtained using the hybrid-PIC code HPHall-2. Section V summarizes the pertinent conclusions of the study. 


\section{Experimental Apparatus}

\section{A. Vacuum Facility}

The study was conducted in the Large Vacuum Test Facility (LVTF) at the Plasmadynamics and Electric Propulsion Laboratory. The LVTF is a 6-m-diamater by 9-m-long stainless-steel clad cylindrical vacuum chamber, and is equipped with seven CVI model TM-1200 cryopumps as well as liquid nitrogen shrouds capable of providing a pumping speed of $245,000 \mathrm{l} / \mathrm{s}$ on xenon. Facility pressure was monitored with a commercially available hotcathode ionization gauge, and a base pressure of $7 \times 10^{-7}$ torr was routinely achieved. At a total mass flow rate of $21.4 \mathrm{mg} / \mathrm{s}$, the facility pressure was $1.5 \times 10^{-5}$ torr, corrected for xenon.

\section{B. Hall Thruster}

The test article for this study is a 6-kW laboratory Hall thruster, the H6, with an approximate throttling range of $100-600 \mathrm{mN}$ thrust, $1000-3000 \mathrm{~s}$ specific impulse, and 1-10 kW discharge power. This thruster has been well documented and has undergone extensive performance and probe testing [15,22-31]. Research-grade xenon (99.999\% pure) was supplied using commercially available mass flow controller with an accuracy of $\pm 1 \%$ full scale. These controllers were calibrated using a constant-volume method that corrected for compressibility effects. The flow rate through the thruster's center-mounted cathode [32] was maintained at $7 \%$ of the anode mass flow rate. The discharge was sustained with a $100 \mathrm{~kW}$ power supply capable of outputting $1000 \mathrm{~V}$ and $100 \mathrm{~A}$. Separate supplies were used to power the magnets, as well as the cathode heater and keeper.

The discharge channel of the H6 is composed of boron nitride and includes replaceable "erosion rings" at the end of the channel to facilitate lifetime studies. For this particular study, a new set of erosion rings were fabricated in order to avoid unnecessary alterations to the original rings. The new rings were machined with a linear chamfer to mimic the erosion pattern observed after approximately 334 hours of operation at an average discharge power of 4.6 $\mathrm{kW}$ (see Figure 1). This was done to match geometries with the original rings such that prior internal measurements [15] could be compared to the results of the present study. Previous studies have shown that pre-machined erosion geometries can give consistent thruster performance to within approximately $2 \%$ of the performance at the target point in life [33]. The erosion profiles shown in Figure 1 were measured using a MicroVal coordinate measuring system with a ruby ball point probe. Due to the low number of operation hours, a linear chamfer provided an excellent approximation to the erosion profile, with differences not exceeding $250 \mu \mathrm{m}$. Prior to the study, the H6 was operated with these rings at the nominal operating condition of $300 \mathrm{~V}$ and $20 \mathrm{mg} / \mathrm{s}$ anode flow rate until the discharge current and oscillations settled to values that were observed with the original rings, which occurred after approximately two hours.
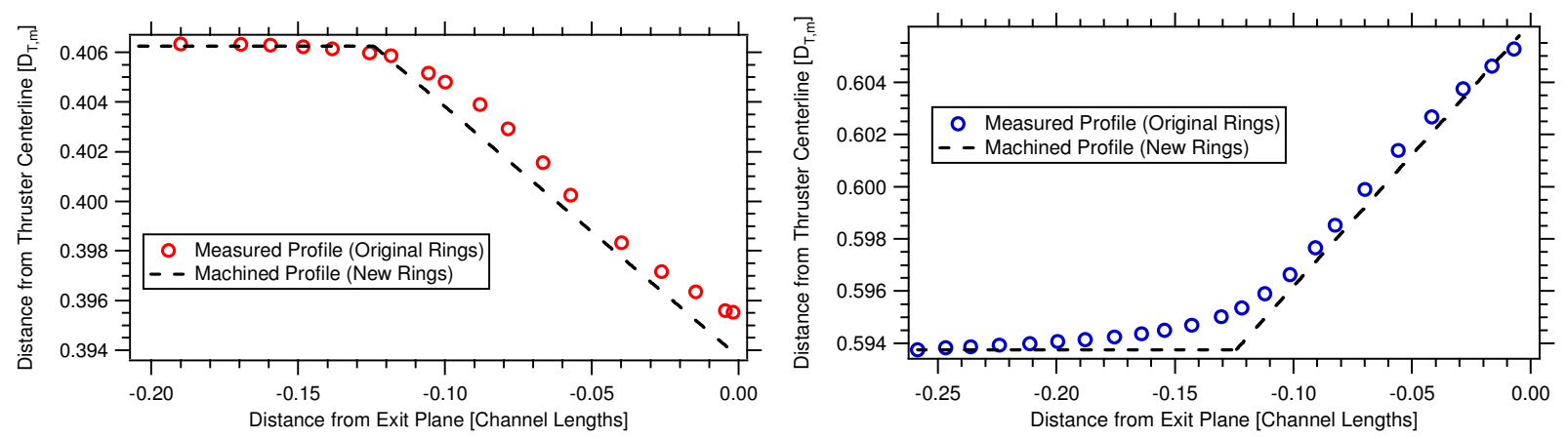

Figure 1. Comparison of measured profiles of the original rings to the linear machined profiles of the new rings. Left: Inner channel ring. Right: Outer channel ring.

The magnetic field topology was maintained as a symmetric configuration about the channel centerline $[3,24]$ for all operating conditions tested. The trim coil was not energized, and the strength was chosen to maximize the thruster anode efficiency as determined by a thrust stand:

$$
\eta_{a}=\frac{T^{2}}{2 \dot{m}_{a} P_{d}},
$$


where $T$ is the measured thrust, $\dot{m}_{a}$ is the anode mass flow rate, and $P_{d}$ is the discharge power. The thrust stand used in this study was a NASA GRC null-type inverted pendulum design, details of which can be found in Refs. [34,35]. Lastly, the cathode keeper and heater were only used during thruster setup, and were turned off during thruster operation and data collection.

\section{Langmuir Probe}

Five Langmuir probes were flush-mounted in each erosion ring near the thruster exit plane in order to measure fundamental plasma properties near the wall such as plasma potential, electron temperature, and plasma number density. This section first describes the mechanical design as well as the data collection techniques used in the study. This is followed by a brief description of the analysis methods used to obtain fundamental plasma properties.

\section{Probe Design}

The final probe design consisted of pure tungsten wire approximately $0.36 \pm$ $0.025 \mathrm{~mm}$ in diameter for the probe tips. These tips were sanded down and inspected for flatness, then inserted into holes within each erosion ring until flush with the surface. High-temperature ceramabond (Aremco 813-A) was used to hold the probe tips in place as well as provide insulation for the first few millimeters of the lead wires. This ceramabond was chosen because of its excellent ability to bond tungsten to boron nitride, as well as its maximum rated temperature of over $1900 \mathrm{~K}$. The remainder of the lead wires were insulated with high-strength fiberglass cloth tape until they were sufficiently beyond the thruster body to avoid large heat loads. The lead wires for the probes on the inner channel wall were routed to the back of the thruster through the central opening used to place the cathode. Ceramic beads were used as extra insulation for portions of the

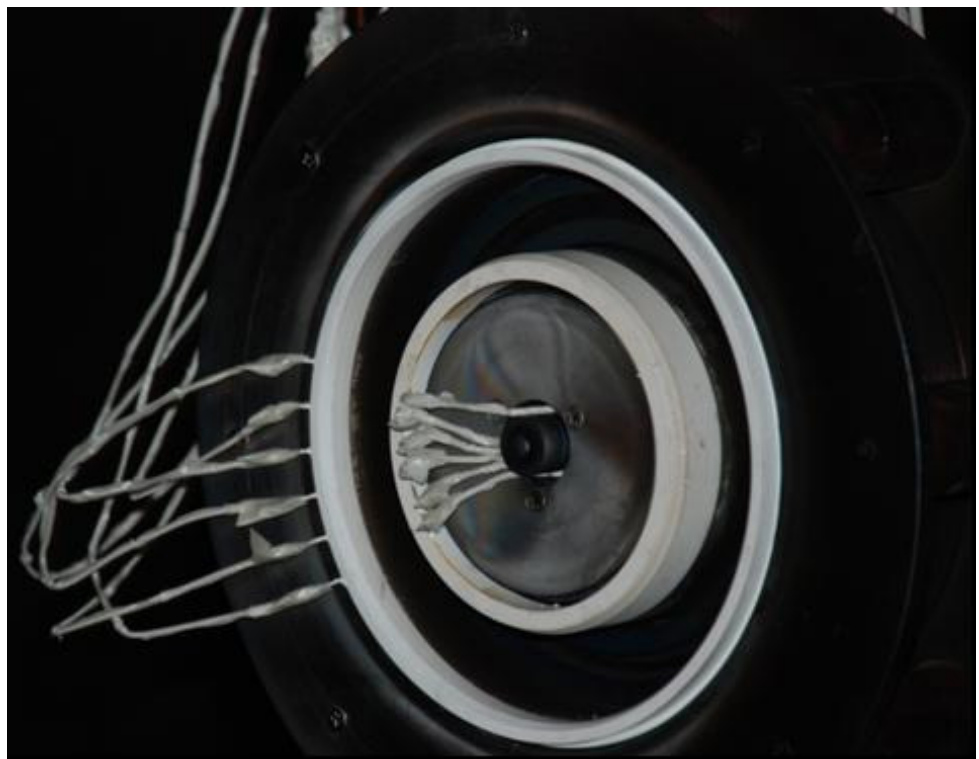

Figure 2. Photograph of the final configuration of flushmounted Langmuir probes along the inner and outer channel walls of the H6 Hall thruster.

wire in close proximity to the cathode keeper. Figure 2 shows the final setup with all probes mounted onto the thruster.

Figure 3 shows the axial locations of each probe with respect to the thruster exit plane. Since this study was focused on obtaining properties in the region of large electric fields and electron temperatures, most of the probes were placed along the chamfer in the last $10 \%$ of the channel where plasma acceleration is expected to occur. The probes were also spaced azimuthally nine degrees apart to avoid probe-to-probe interactions [9] as well as ease installation. Furthermore, the inner and outer erosion rings were offset azimuthally to avoid probe-to-probe interactions between the two channel walls. A sixth probe was placed in each ring to serve as a null probe that characterizes the line capacitive effects [36]. This probe was inserted into a blind hole to ensure complete insulation from the plasma (see Figure 4). 


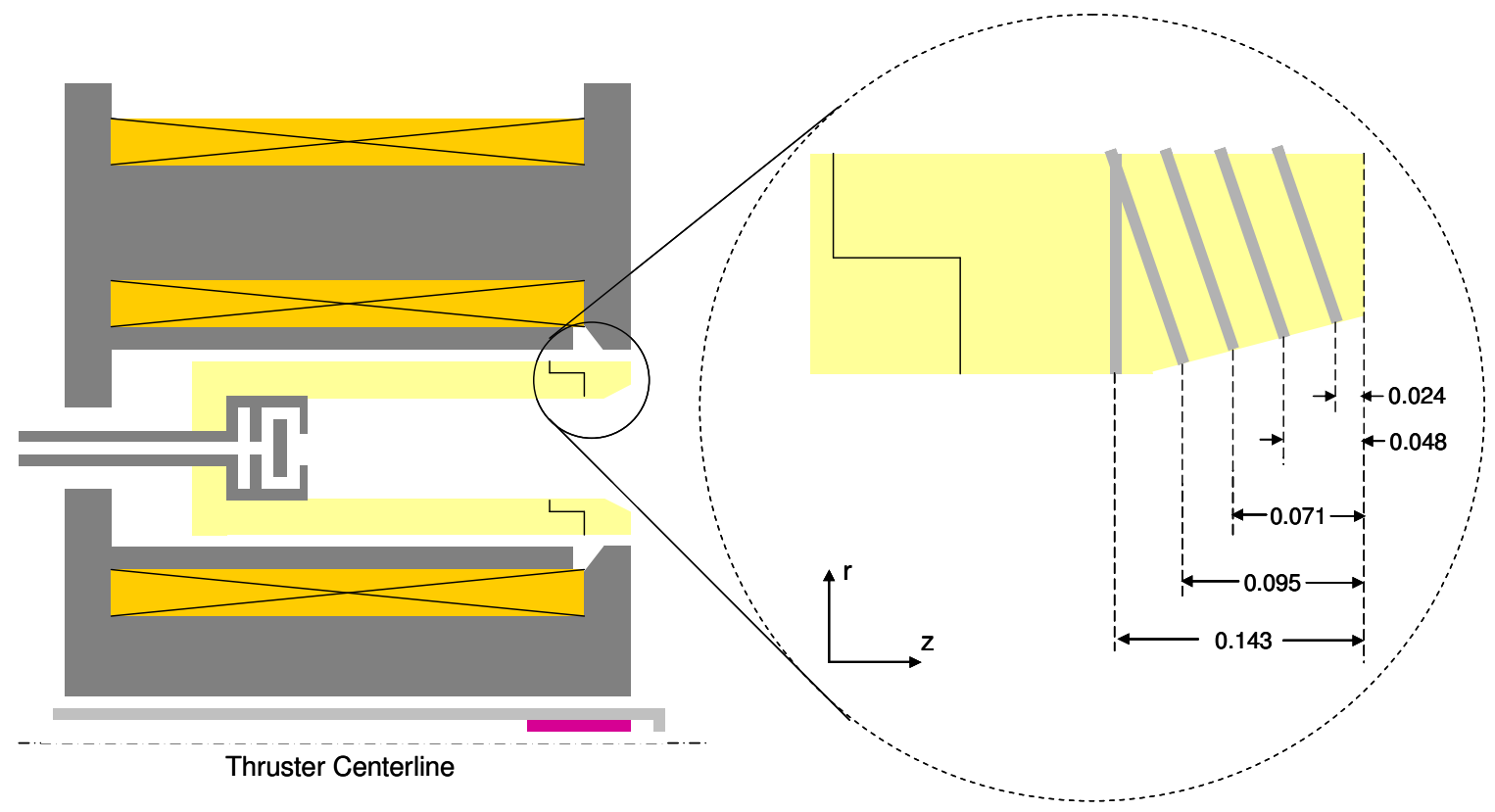

Figure 3. Schematic showing the locations of each probe with respect to the thruster exit plane. Dimensions are in units of channel lengths. Not to scale.

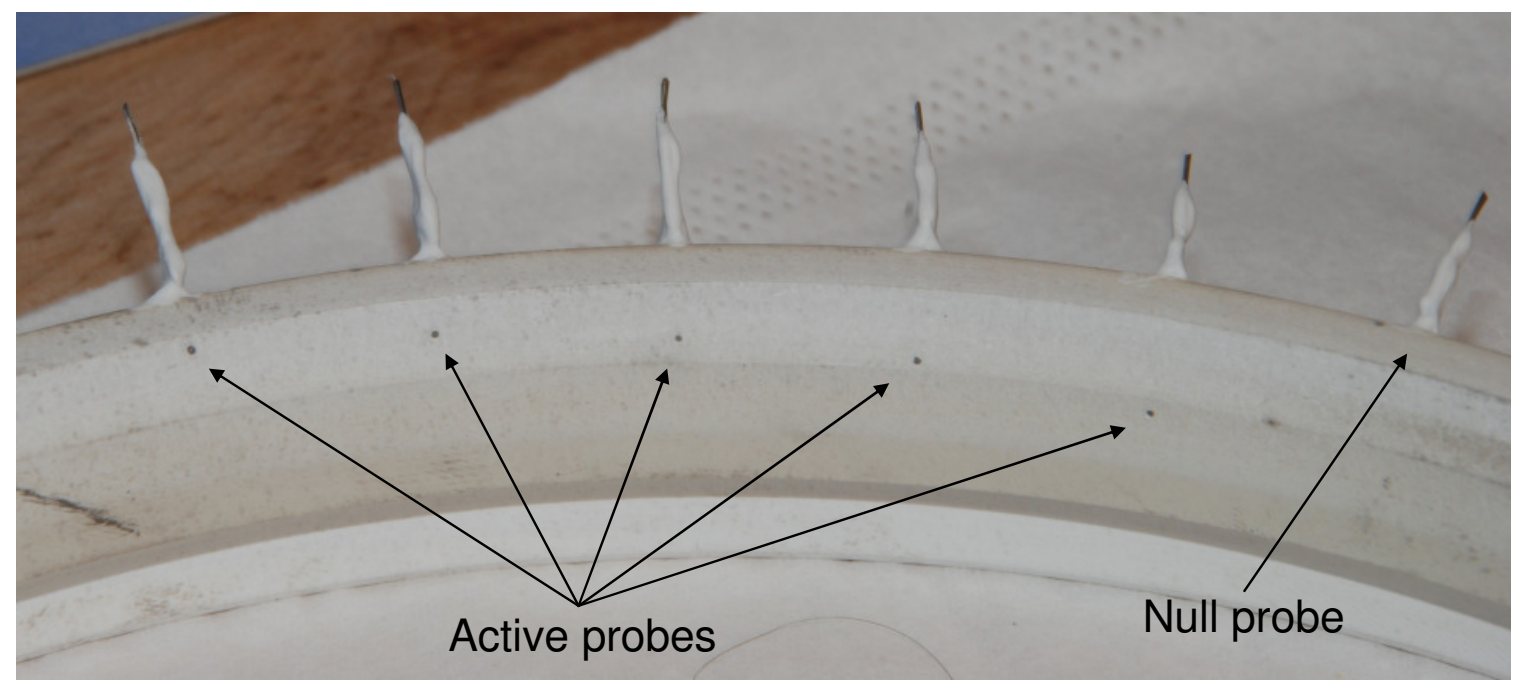

Figure 4. Photograph of all five flush-mounted probes azimuthally spaced along the outer channel erosion ring prior to installation on the thruster. The null probe has no exposed area and is only used to characterize line capacitance.

\section{Data Acquisition}

Since direct comparisons of plasma properties between inner and outer channel walls were desired, the measurement circuit was designed to simultaneously measure I-V characteristics of four probes (two active probes and two null probes). Figure 5 shows an electrical diagram of the measurement circuit used in the study. The current for each probe was measured using $100-\Omega, 500-\mathrm{mW}$ thin-film resistors, while the voltage was monitored using a voltage divider comprised of 10-M $\Omega$ and 0.24-M $\Omega$ thin-film resistors. Each signal was isolated from the data acquisition system (DAQ) using voltage-following isolation amplifiers with a bandwidth of $20 \mathrm{kHz}$. Blocking diodes were placed in parallel with the current resistors to protect the isolation amplifiers from large current spikes. 


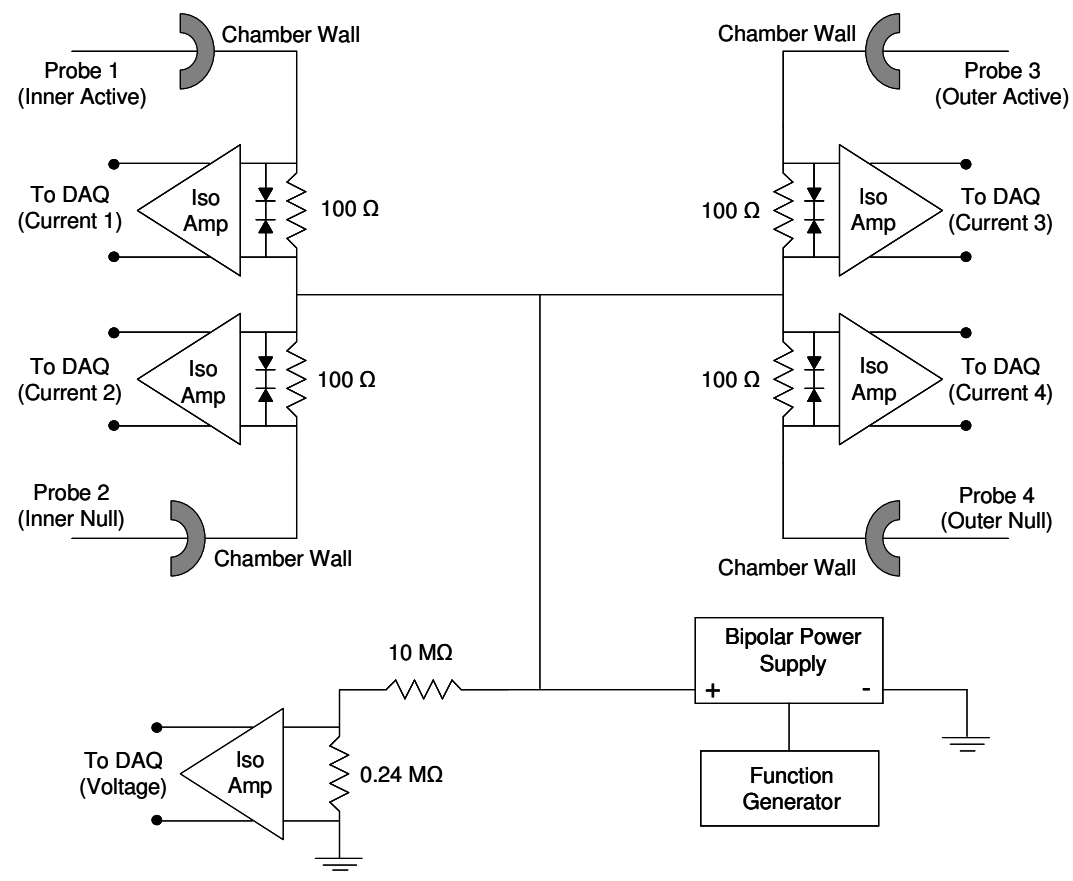

Figure 5. Electrical diagram of the measurement circuit used with the wall probes. Four current sensors were used to simultaneously run each pair of inner and outer wall probes as well as the null probes.

The voltage and current signals were calibrated at DC prior to and following the study and displayed excellent linearity and repeatability. The probes were operated with a bipolar power supply driven by a function generator. Voltage was applied using a symmetric triangle waveform at a frequency of $20 \mathrm{~Hz}$, well within the bandwidth of the isolation amplifiers. Data was collected and stored using an 8-channel DAQ capable of scanning at $2 \mathrm{MHz}$ across each channel. For this study, the scan rate was maintained at $40 \mathrm{kHz}$, resulting in approximately 1000 data points per I-V characteristic. Two hundred traces were taken per probe, per operating condition, and averaged before any analysis was performed.

\section{Data Analysis Methods}

The analysis techniques used to determine fundamental plasma properties from flush-mounted Langmuir probes largely follow simple Langmuir probe theory, and have been previously discussed in detail in Ref. [20]. However, the previous method of correcting the ion saturation branch for sheath expansion was deemed inadequate, and a new model was formulated specifically for flush-mounted probe geometries in Hall thrusters.

Sheridan's model of sheath expansion around free-floating planar probes [37] was previously used in Ref. [20] to correct the ion saturation branch and determine the true saturation current. However, it was found that the presence of a dielectric material surrounding the probe significantly affected the sheath expansion characteristics and necessitated a new model which accounts for the specific boundary conditions. The two-dimensional hybrid-PIC code CEX2D, originally developed by Ira Katz at the Jet Propulsion Laboratory (JPL) [38], was used to characterize the sheath expansion around a flush probe at a variety of bias voltages, electron temperatures, and plasma densities. The method of characterization was similar to that of Sheridan: to determine the area expansion ratio as a function of normalized probe radius and bias voltage. Since the details of developing this model are beyond the scope of this paper, only the final sheath expansion formulas will be presented here.

Based on the results from Ref. [21], the floating potential of the dielectric wall was calculated using the Hobbs and Wesson solution of space-charge-limited emission [39], which accounts for the effects of secondary electron emission from the wall. It was found that the sheath expansion was highly dependent on the floating potential of the adjacent dielectric material, as well as the electron temperature at which the onset of the charge saturation regime (CSR) occurs. At higher electron temperatures, the secondary electron emission from the wall becomes spacecharge-limited, and the sheath potential of the dielectric material reduces to approximately one electron temperature. Due to these features, the following non-dimensional parameters were used to characterize the sheath expansion: 


$$
\begin{gathered}
\rho_{p}=\frac{r_{p}}{\lambda_{D e}} \\
\mu_{p}=-\frac{\phi_{\text {probe }}-\phi_{\text {wall }}}{T_{e}}, \mu_{0}=-\frac{\phi_{\text {wall }}}{T_{e}},
\end{gathered}
$$

where $r_{p}$ is the probe radius, $\lambda_{D e}$ is the Debye length, $T_{e}$ is the electron temperature in $\mathrm{eV}, \phi_{\text {probe }}$ is the probe potential, and $\phi_{\text {wall }}$ is the dielectric wall potential. All potentials are with respect to the local plasma potential. The final sheath expansion model is

$$
\begin{gathered}
\frac{A_{s}}{A_{p}}=1+C\left(\mu_{0}\right) \rho_{p}^{m\left(\mu_{o}\right)} \mu_{p}, \\
C\left(\mu_{0}\right)=\left\{\begin{array}{l}
0.2985, \mu_{0}>1.02 \\
0.4094, \mu_{0} \leq 1.02
\end{array},\right. \\
m\left(\mu_{0}\right)=\left\{\begin{array}{l}
-0.7978, \mu_{0}>1.02 \\
-0.8495, \mu_{0} \leq 1.02
\end{array},\right.
\end{gathered}
$$

where $A_{s}$ is the sheath area and $A_{p}$ is the probe area. Thus, the above model can be used at each bias voltage to "correct" the probe current by determining the amount of ion current collected had there been no sheath expansion. This correction is an iterative process since the Debye length, and thus the plasma density, need to be known to properly correct the ion saturation branch and calculate the plasma density. Figure 6 shows an example of this correction on a sample I-V characteristic from this study. It is evident that the corrected data is much flatter, allowing the ion saturation current to be easily determined. Due to the inherent noise in the data, the ion saturation current was found by averaging from the lowest applied potential to one electron temperature below the measured floating potential.

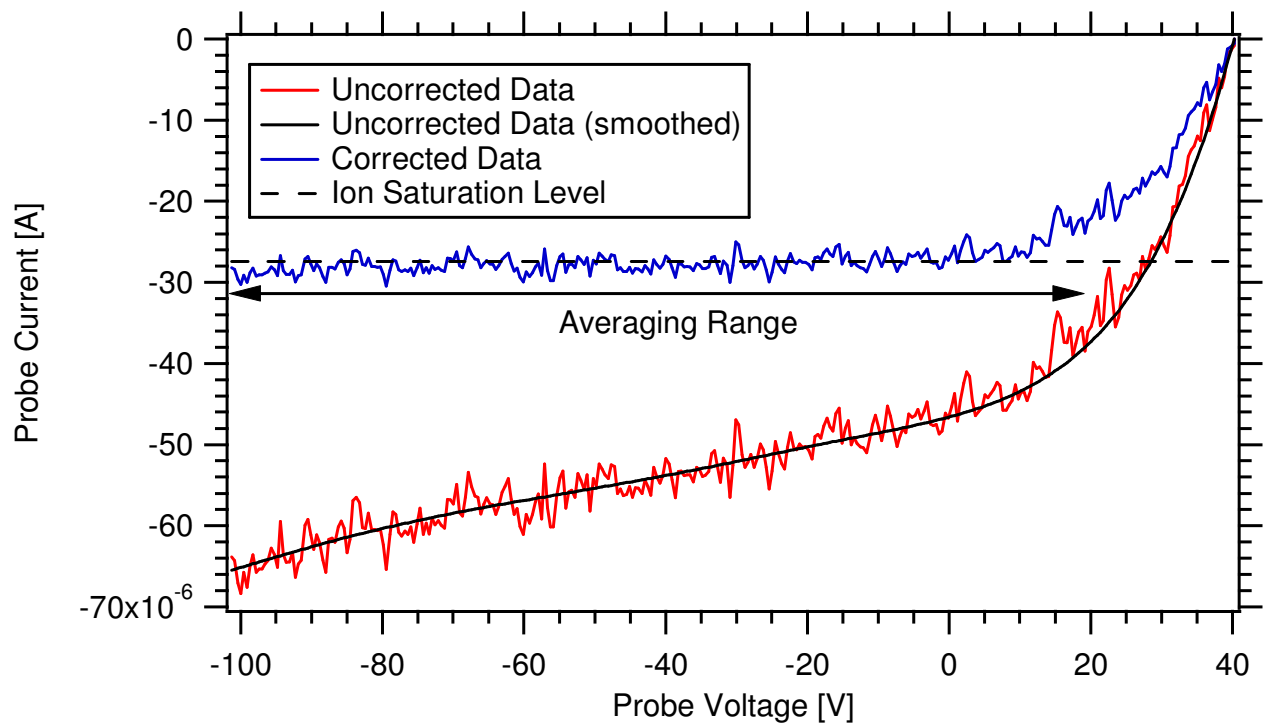

Figure 6. Comparison of corrected vs. uncorrected data in the ion saturation branch of an I-V characteristic from a flush probe. The corrected data is much flatter, making the ion saturation current easily determined. 


\section{Results}

Relevant plasma parameters were measured near the exit plane of the H6 Hall thruster using five flush-mounted Langmuir probes along each channel wall. Axial profiles of plasma potential, electron temperature, and ion number density will be compared to prior internal data [15] taken closer to channel centerline in order to characterize the near-wall plasma. This section will begin with a brief description of internal data taken by Reid [15], followed by comparisons of each plasma parameter at the nominal operating condition of $300 \mathrm{~V}$ and $20 \mathrm{mg} / \mathrm{s}$ anode flow rate.

\section{A. Prior Internal Measurements}

Spatially resolved distributions of plasma potential, electron temperature, and ion number density were taken by Reid [15] inside the discharge channel of the H6 Hall thruster. Figure 7 shows the spatial domain of these measurements with respect to the thruster anode and channel walls.

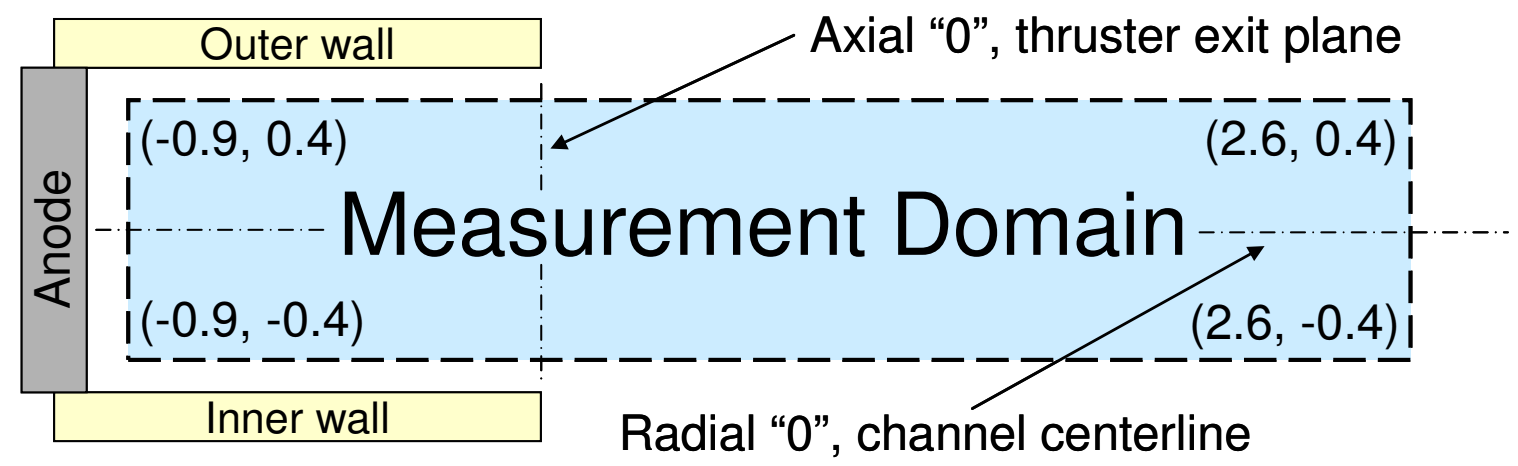

Figure 7. Diagram illustrating the domain of prior internal measurements taken by Reid. Corner coordinates are given in $(\mathbf{z}, \mathbf{r})$ format, with axial units normalized by channel length and radial units normalized by channel width. Not to scale.

Measurements of electron temperature and ion number density were taken with a cylindrical Langmuir probe, while measurements of the local plasma potential were taken with a floating emissive probe. Both probes were mounted onto a High-speed Axial Reciprocating Probe stage (HARP) to minimize residence time and probe heat loading in the channel and ensure probe survival. Each probe was injected into the thruster in the axial direction at various radial locations to fully map the measurement domain. Reid had investigated numerous analysis techniques to determine the ion number density, including thin sheath theory, orbit-motion-limited theory, and a blending technique of both methods that incorporated a self-consistently calculated Debye length. The blending technique was found to yield the most physically reasonable density distributions at nominal conditions, and therefore will be the data presented here.

In the following sections, comparisons will be made between data taken along the channel walls to those taken by Reid within the channel. Two radial locations have been chosen for comparison to the data along the walls: channel centerline, and the location closest to the channel wall. The radial location of $r=-0.4$ channel widths will be called the "bulk plasma inner bound" while the location of $r=+0.4$ channel widths will be called the "bulk plasma outer bound."

\section{B. Plasma Potential}

Figure 8 and Figure 9 show the comparison of axial profiles of plasma potential between the channel walls and the two radial locations within the bulk plasma, at the nominal operating condition of $300 \mathrm{~V}$ and $20 \mathrm{mg} / \mathrm{s}$. All values reported are with respect to cathode potential; measurements taken with respect to facility ground were corrected for the cathode-to-ground potential, typically around $-10 \mathrm{~V}$. Based on the uncertainties associated with determining the plasma potential using the derivative method [20], error bars of $\pm 20 \mathrm{~V}$ were placed on the data derived from the flush-mounted Langmuir probes.

The acceleration zone is taken to be where the plasma potential rapidly drops, and begins in the last $10 \%$ of the thruster channel. Upstream of this zone, the plasma potential is found to be highly uniform in both the axial and radial directions, with differences not exceeding $5 \mathrm{~V}$. This uniformity extends all the way to the channel walls, indicating that there are negligible axial and radial electric fields for approximately $90 \%$ of the channel. In the remaining $10 \%$ of the channel, the plasma near the channel walls appear to accelerate further upstream compared to 
the bulk plasma. While this difference in acceleration zone is only 5\% of the channel, the rapid drop in plasma potential creates large potential differences in the radial direction. Near the exit plane, the resulting radial electric fields approach 40-50 V/mm, which are comparable to the axial electric fields within the acceleration zone [15]. It is worth noting that this could be an underestimate of the radial electric field; it is uncertain whether the observed potential difference occurs within a shorter distance than between the wall and the bulk plasma bounds.

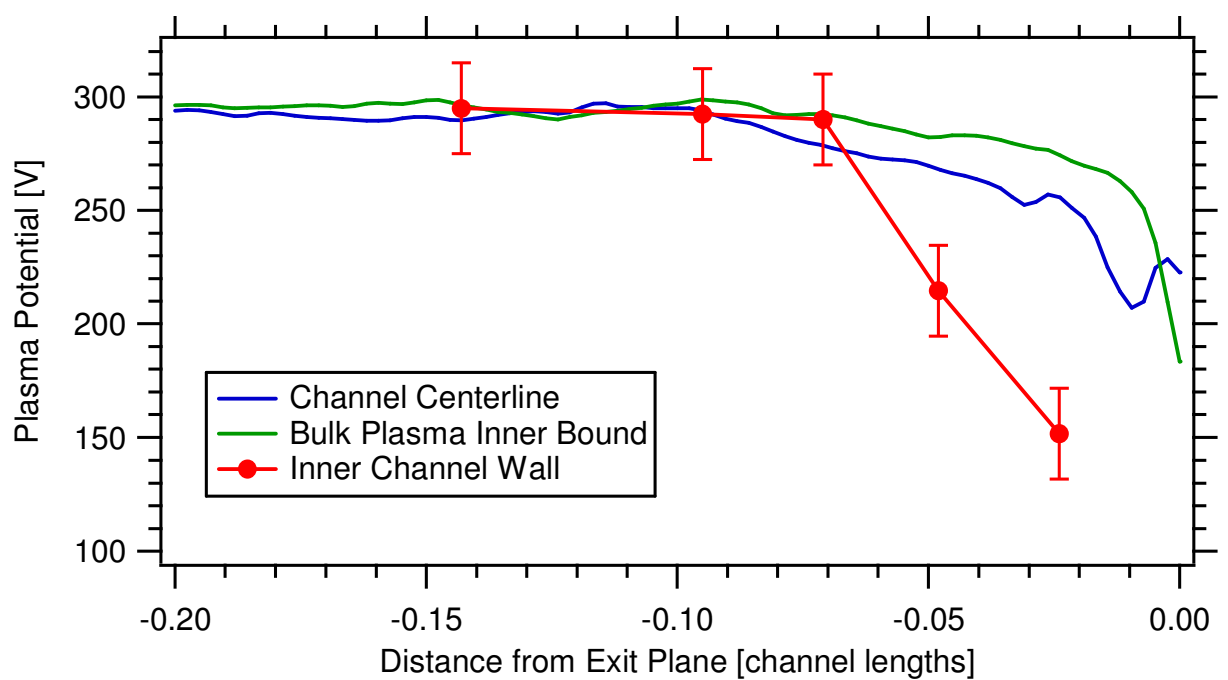

Figure 8. Comparison of axial profiles of plasma potential at three different radial locations within the channel, under the nominal operating condition of $300 \mathrm{~V}, 20 \mathrm{mg} / \mathrm{s}$ anode flow rate. The plasma begins to accelerate further upstream when close to the channel wall.

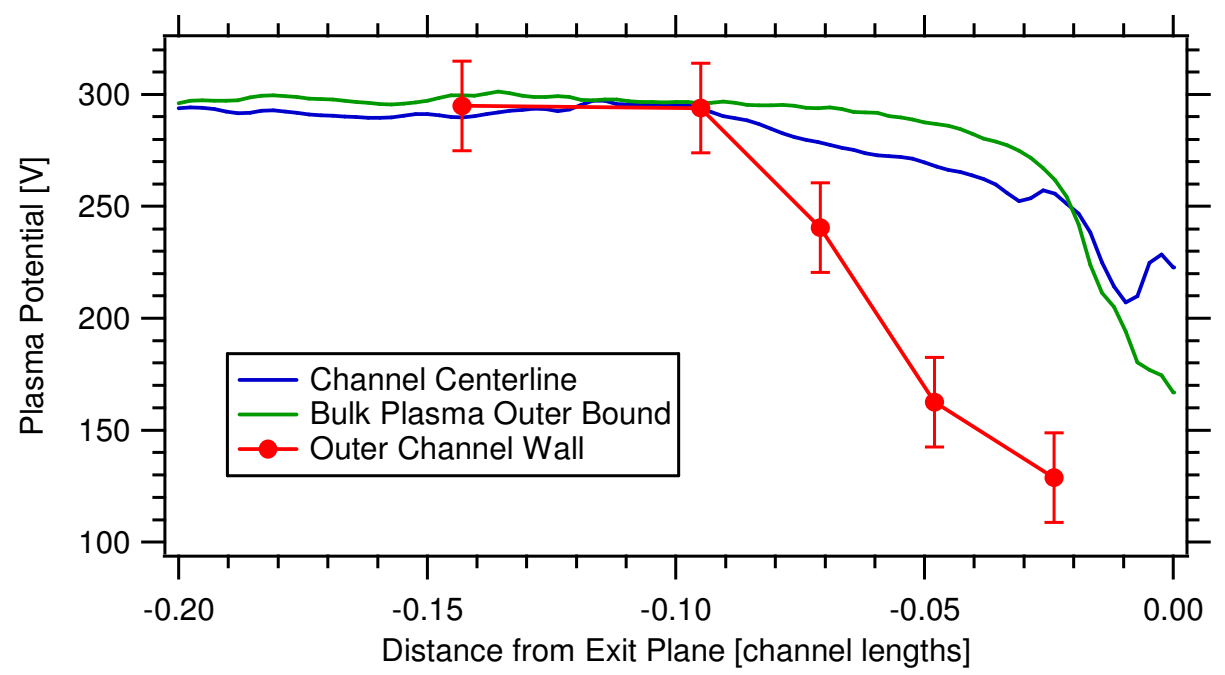

Figure 9. Comparison of axial profiles of plasma potential at three different radial locations within the channel, under the nominal operating condition of $300 \mathrm{~V}, 20 \mathrm{mg} / \mathrm{s}$ anode flow rate. The plasma begins to accelerate further upstream when close to the channel wall.

Figure 10 compares the axial profiles of plasma potential between each channel wall at $300 \mathrm{~V}, 20 \mathrm{mg} / \mathrm{s}$ anode flow rate. Despite the use of a symmetric magnetic field, which largely influences the induced electric field, the plasma along the outer channel walls appears to accelerate slightly upstream of the plasma along the inner wall. However, this variation is minor and the axial electric fields along inner and outer walls are roughly equal. The observed asymmetry is also present in measured electron temperature profiles, and will be discussed in further detail in Section IV. 


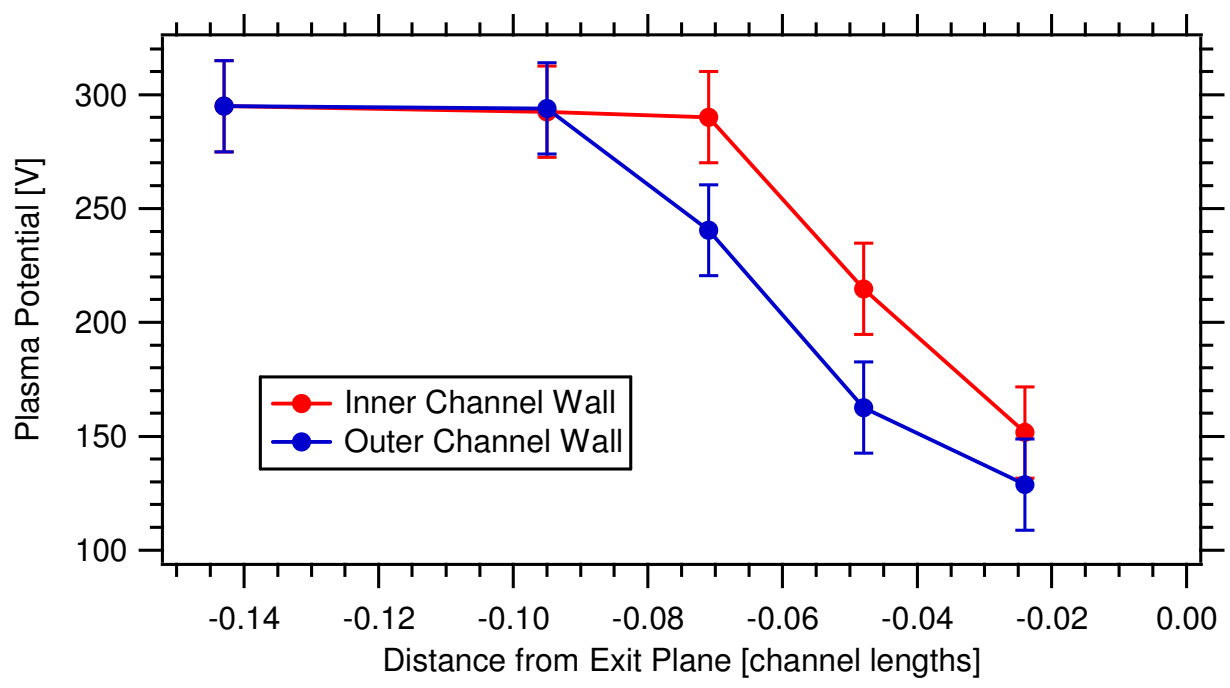

Figure 10. Comparison of axial profiles of plasma potential between inner and outer channel walls at $300 \mathrm{~V}$, $20 \mathrm{mg} / \mathrm{s}$ anode flow rate. Despite the use of a symmetric magnetic field topology, the plasma along the outer wall begins to accelerate further upstream than the plasma along the inner wall.

\section{Electron Temperature}

Figure 11 and Figure 12 show comparisons of the axial profiles of electron temperature between the channel walls and within the bulk plasma, at the nominal operating condition of $300 \mathrm{~V}$ and $20 \mathrm{mg} / \mathrm{s}$ anode flow rate. Based on the variation of possible lines that could be fit to the electron retarding region of the probe's I-V characteristic (in semi-log form), uncertainty bars of $\pm 15 \%$ were placed on the data taken along the channel walls.

Along both inner and outer channel walls, the peak electron temperature appears to be consistent with those found within the bulk discharge. The location of this peak is also fairly consistent, with differences in location being within $2 \%$ of the channel length. However, this location occurs slightly upstream of the beginning of the acceleration zone in the bulk discharge, while coinciding with the beginning of the acceleration zone along the channel walls. Given the general agreement of peak value and location between the channel walls and bulk plasma, it appears that the isothermal approximation along field lines is valid since they are nearly radial in this portion of the channel.

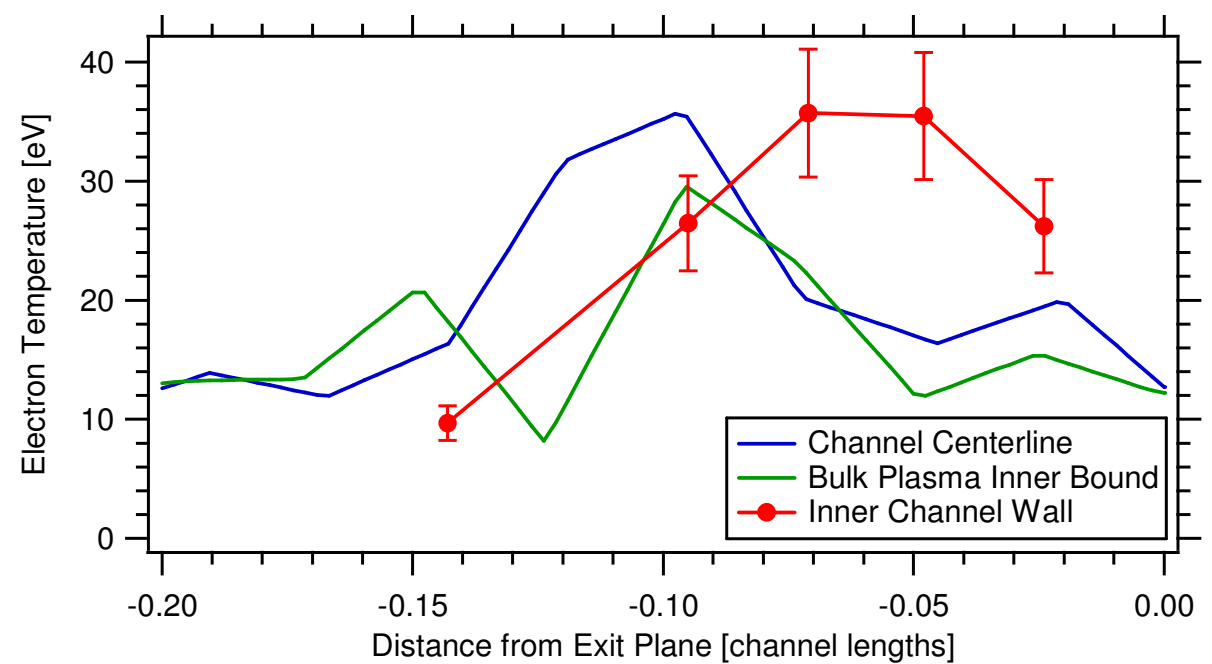

Figure 11. Comparison of axial profiles of electron temperature at three different radial locations, at the nominal operating condition of $300 \mathrm{~V}, 20 \mathrm{mg} / \mathrm{s}$ anode flow rate. The peak electron temperatures are comparable, but occur slightly downstream close to the wall. 


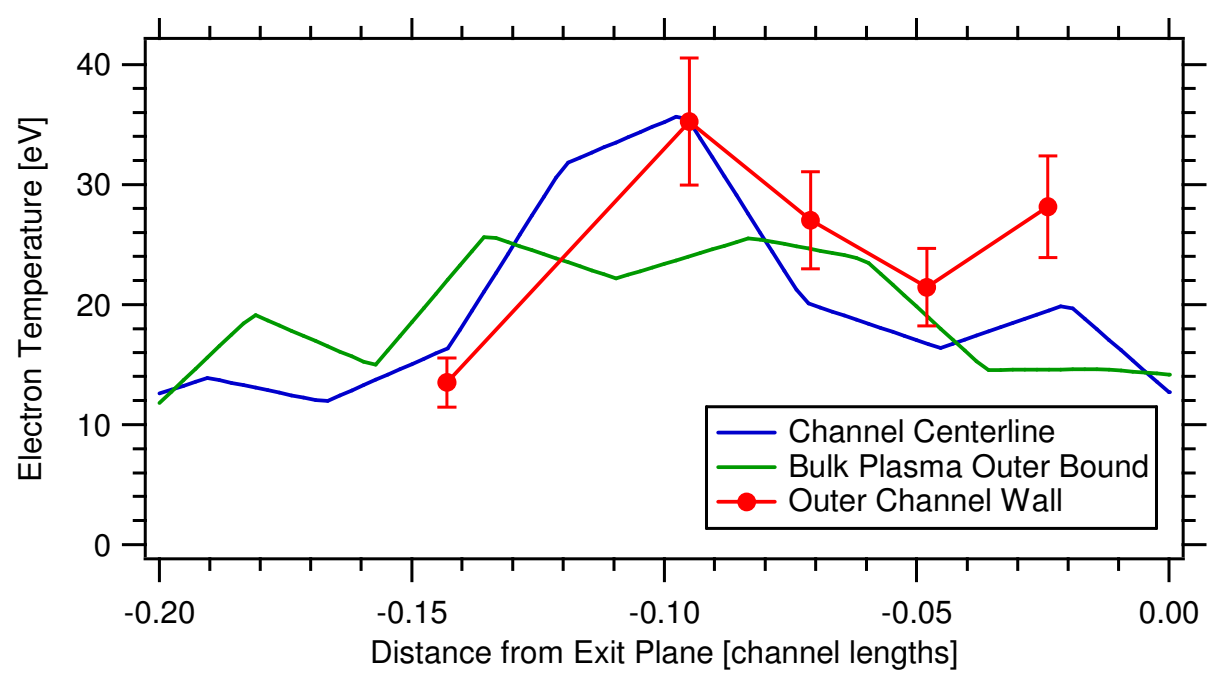

Figure 12. Comparison of axial profiles of electron temperature at three different radial locations, at the nominal operating condition of $300 \mathrm{~V}, 20 \mathrm{mg} / \mathrm{s}$ anode flow rate. The peak electron temperatures are comparable at all radial locations.

Figure 13 compares the axial profiles of electron temperature between inner and outer channel walls, at nominal conditions of $300 \mathrm{~V}$ and $20 \mathrm{mg} / \mathrm{s}$ anode flow rate. While peak electron temperatures are very consistent across the channel, the location of this peak is slightly upstream along the outer wall compared to the inner wall. This trend is consistent with the locations of the acceleration zone along both channel walls. The peak electron temperature of 35 $\mathrm{eV}$, roughly $10 \%$ of the discharge voltage, is consistent with prior internal measurements [13-15].

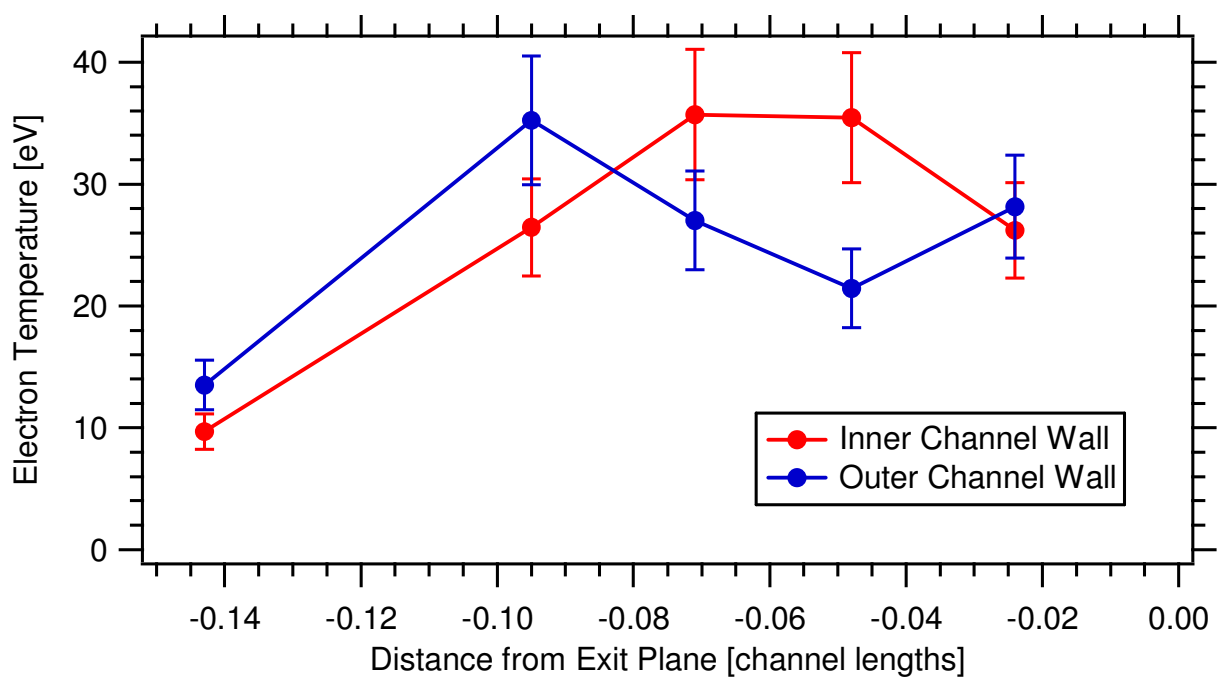

Figure 13. Comparison of axial profiles of electron temperature between inner and outer channel walls, at $300 \mathrm{~V}$ and $20 \mathrm{mg} / \mathrm{s}$ anode flow rate. Peak electron temperatures are consistent between the two walls, while the peak along the outer wall occurs slightly upstream of the peak along the inner wall.

\section{Ion Number Density}

The ion number density in this study was calculated using two different methods. These methods are only briefly described here; further details can be found in Ref. [20]. The first method assumes that the ion saturation current is equal to the Bohm current, i.e. ions enter the sheath at the Bohm velocity:

$$
j_{i, s a t}=e n_{i} \sqrt{\frac{e T_{e}}{M_{i}}},
$$


where $j_{i, s a t}$ is the ion saturation current density, $e$ is the elementary charge, $n_{i}$ is the ion number density, $T_{e}$ is the electron temperature in $\mathrm{eV}$, and $M_{i}$ is the ion mass. Based on the uncertainty associated with measuring the ion saturation current and electron temperature, the uncertainty associated with this calculation is $\pm 47.5 \%$. This method will be called the "Bohm" method.

The second method takes into account the possibility that ions will enter the sheath supersonically; this will typically occur within the acceleration zone of the thruster. Thus, the ion saturation current is taken to be comprised of a beam of ions entering the sheath at a certain normal velocity:

$$
j_{i, s a t}=e n_{i} u_{\perp}=e n_{i} \sqrt{\frac{2 e \varepsilon_{\perp}}{M_{i}}}
$$

where $u_{\perp}$ is the normal velocity, $\varepsilon_{\perp}$ is the normal energy, and the rest of the symbols have their usual meaning. Based on the uncertainty in measuring the ion saturation current and normal energy, the uncertainty associated with this calculation is $\pm 60 \%$. This method will be called the "Beam" method.

Figure 14 and Figure 15 show comparisons of the calculated ion number density between the walls and the bulk plasma at the nominal operating condition of $300 \mathrm{~V}$ and $20 \mathrm{mg} / \mathrm{s}$ anode flow rate. The data at $\mathrm{z}=-0.095 \mathrm{channel}$ lengths along the inner wall are no included due to the probe showing signs of leakage current [40]. The presence of leakage current significantly affected measurements of floating potential and ion saturation current, but did not seem to affect electron temperature and plasma potential. Thus, the data from this probe were reported in the previous sections, but not in the ion density profiles below.

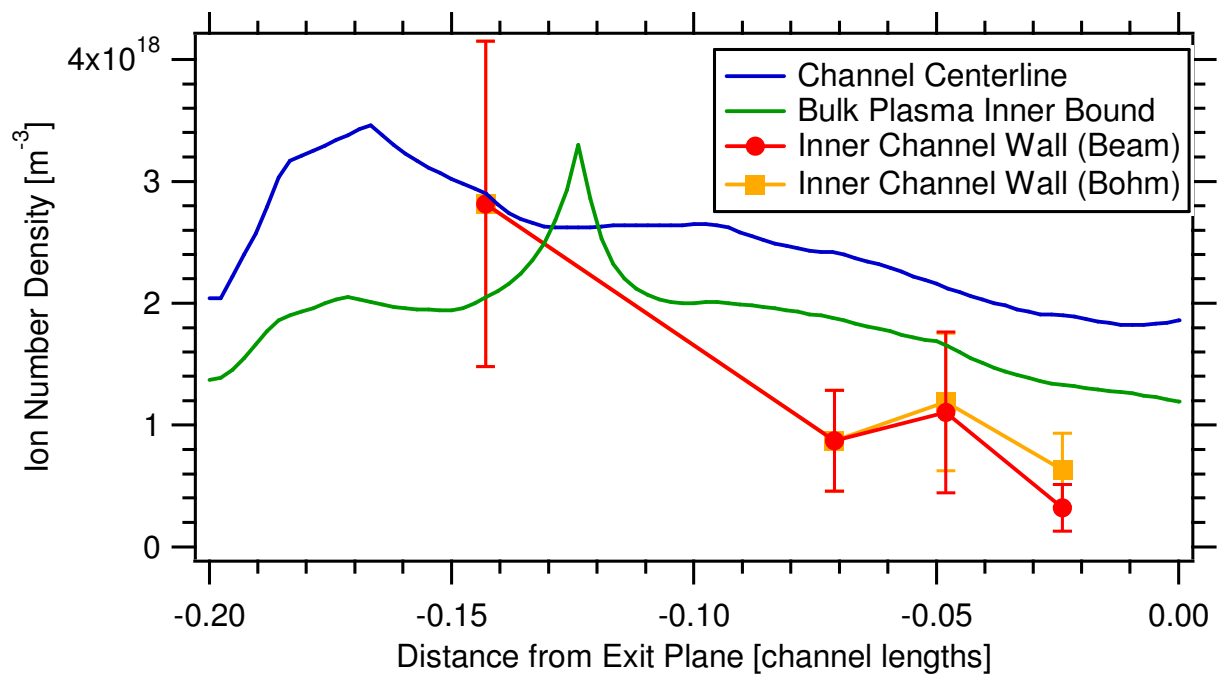

Figure 14. Comparison of axial profiles of ion number density at three different radial locations, at $300 \mathrm{~V}$ and $20 \mathrm{mg} / \mathrm{s}$ anode flow rate. Near the thruster exit plane, the difference between the plasma at centerline and that at the wall can approach an order of magnitude. 


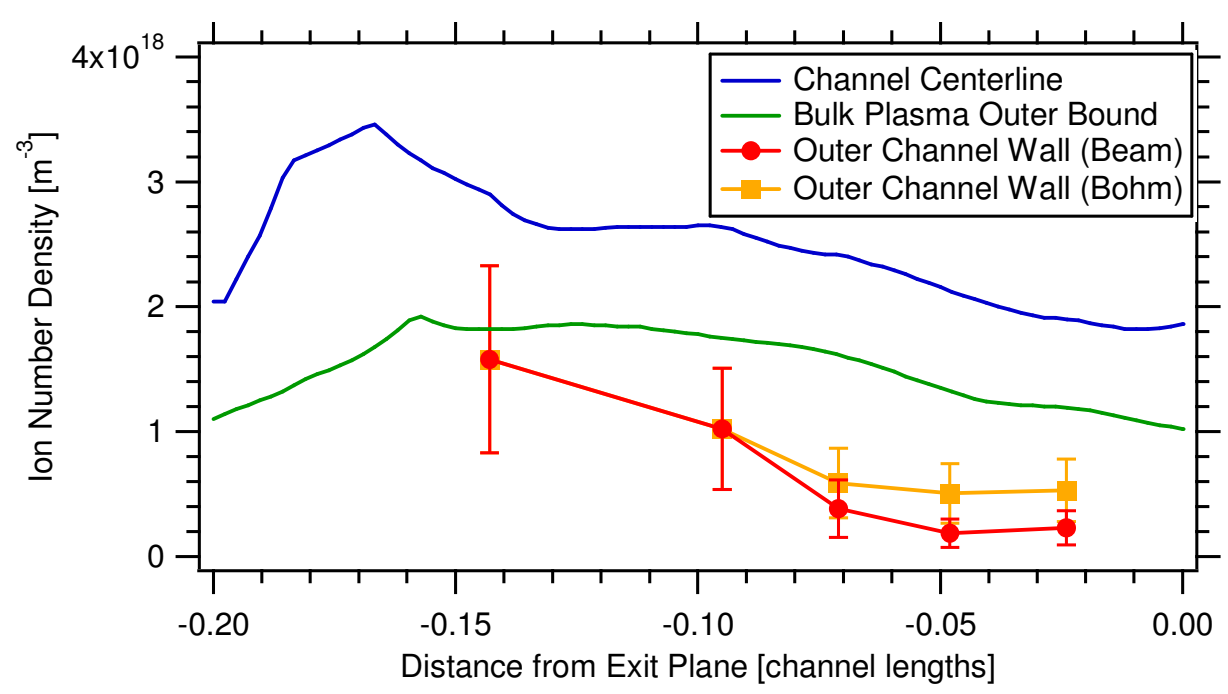

Figure 15. Comparison of axial profiles of ion number density at three different radial locations, at $300 \mathrm{~V}$ and $20 \mathrm{mg} / \mathrm{s}$ anode flow rate. Near the thruster exit plane, the difference between the plasma at centerline and that at the wall can approach an order of magnitude.

Along both inner and outer channel walls, the ion number density is lower than in the bulk plasma. Prior internal measurements show a significant drop in density even between channel centerline and the bulk plasma bounds. While the difference between densities at channel centerline and the wall is limited to 2-3X upstream of the acceleration zone, this difference can approach an order of magnitude near the thruster exit plane (see Table 1). It is worth noting that, as expected, the two methods of calculating number density yield identical answers until the acceleration zone is reached. Once the plasma accelerates, the ions begin to enter the sheath supersonically, causing the Bohm approximation to differ from the Beam calculation by roughly a factor of two.

Table 1. Comparison of ion number densities between the inner and outer walls and channel centerline at $300 \mathrm{~V}$ and $20 \mathrm{mg} / \mathrm{s}$ anode flow rate. Number densities at the wall were calculated using the Beam method, and the location is in units of channel lengths from the thruster exit plane.

\begin{tabular}{ccc} 
Location & $\mathbf{n}_{\text {wall }} / \mathbf{n}_{\text {centerline }}($ Inner Wall $)$ & $\mathbf{n}_{\text {wall }} / \mathbf{n}_{\text {centerline }}($ Outer Wall $)$ \\
\hline$z=-0.143$ & 0.98 & 0.55 \\
$z=-0.095$ & N/A & 0.39 \\
$z=-0.071$ & 0.36 & 0.16 \\
$z=-0.048$ & 0.52 & 0.088 \\
$z=-0.024$ & 0.17 & 0.12
\end{tabular}

Figure 16 compares the axial profiles of ion number density between the inner and outer channel walls at $300 \mathrm{~V}$ and $20 \mathrm{mg} / \mathrm{s}$ anode flow rate. The calculated number density is consistently higher along the inner wall, with differences of approximately 1.5-2X upstream of the acceleration zone. As the exit plane is approached, the difference diminishes and the plasma becomes more symmetric. This slight asymmetry is once again surprising given the use of a symmetric magnetic field topology. However, differences have been observed in both plasma potential and electron temperature, and this asymmetry will be discussed further in Section IV. 


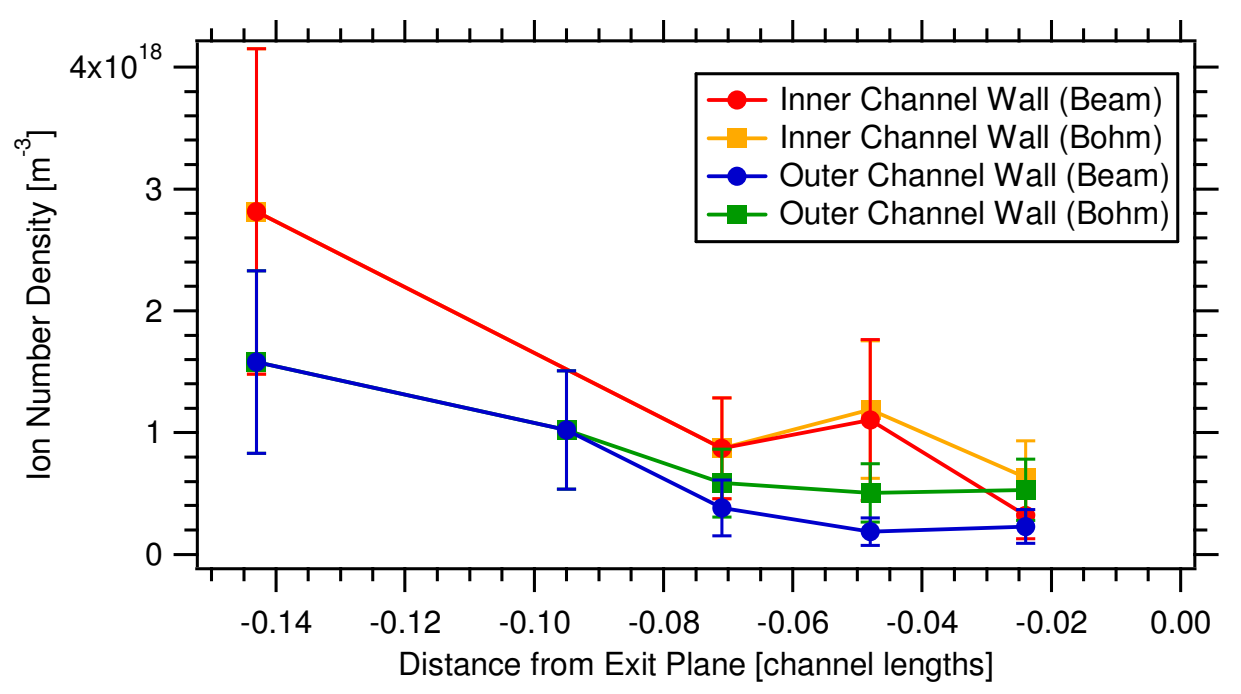

Figure 16. Comparison of axial profiles of ion number density between inner and outer channel walls, at the nominal operating condition of $300 \mathrm{~V}$ and $20 \mathrm{mg} / \mathrm{s}$. The density along the inner wall is consistently higher than along the outer wall, with the difference diminishing as the exit plane is approached.

\section{Discussion}

Five Langmuir probes were flush-mounted into each erosion ring of the H6 Hall thruster, and various plasma properties were measured as a function of axial distance near the exit plane. It was found that the plasma begins to accelerate further upstream when closer to the wall, electron temperature profiles are fairly consistent across the channel, and the ion number density near the channel walls can differ from the density at channel centerline by an order of magnitude. The implications of these results will be discussed in the following section. Afterward, the asymmetry observed between the inner and outer channel walls will be validated through the use of erosion profiles and magnetic field simulations. Lastly, the data from this study will be compared to computational results from the hybrid-PIC program HPHall-2.

\section{A. "Defocusing" Near the Walls and the Isothermal Assumption}

In Section III, it was shown that the acceleration zone near the wall begins upstream of the acceleration zone at channel centerline. Due to the rapid drop of plasma potential within this zone, this axial shift creates large radial electric fields directed towards the channel walls. This trend is rather surprising given the "plasma lens" magnetic field topology. Neglecting inertial terms, the electron momentum equation along magnetic field lines simplifies to the well known Boltzmann relation of thermalized potential [41]:

$$
\phi=\phi_{0}+T_{e} \ln \left(\frac{n}{n_{0}}\right)
$$

where $\phi$ is the thermalized potential, $T_{e}$ is the electron temperature in $\mathrm{eV}, n$ is the plasma number density, and $\phi_{0}$ and $n_{0}$ are reference values. Without inertial terms, the electric field along a magnetic field line is balanced by the electron pressure. Equation 5 assumes that the electron temperature is constant along a magnetic field line. Based upon the profiles presented in Section III, this was found to be a reasonable assumption.

If the number density is roughly uniform along a magnetic field line, then Eq. 5 shows that the potential is roughly constant along that line to within one electron temperature. Therefore, magnetic field lines can be treated as equipotentials within the thruster. Figure 17 shows the expected axial profiles of plasma potential given the assumption that magnetic field lines are equipotentials. For a plasma lens topology, the acceleration zone close to the wall should move downstream, and contain larger axial electric fields. This shift in acceleration zone will create radial electric fields that point towards channel centerline, diverting ions away from the walls. None of these trends are observed in the present study. However, since the magnetic field lines in the acceleration zone are primarily radial, none of these trends are expected to be highly pronounced. 


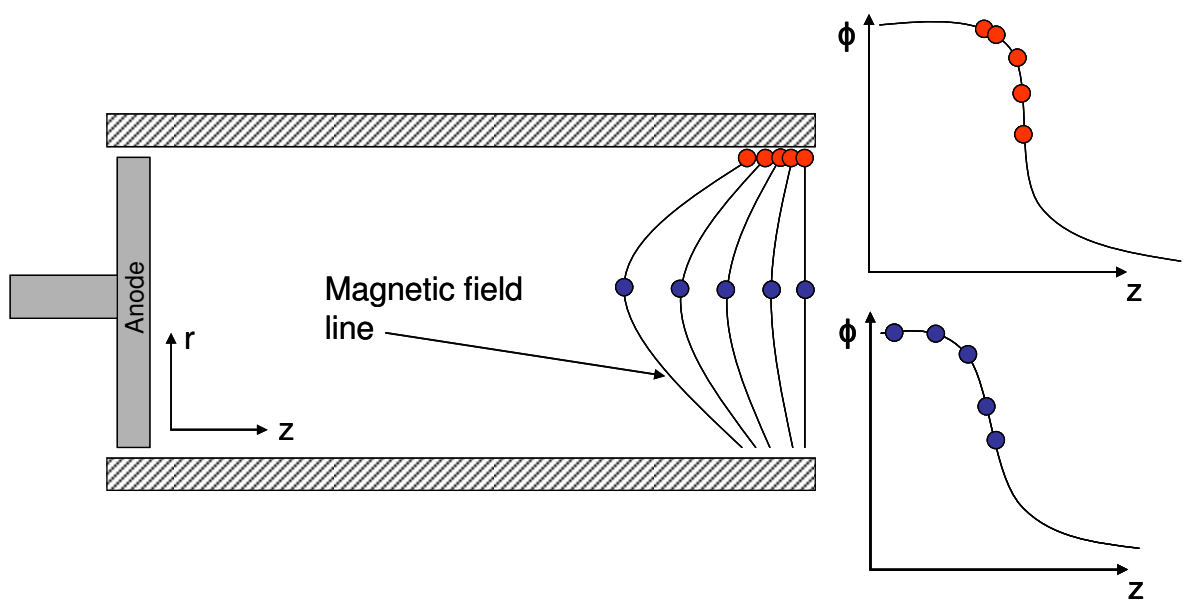

Figure 17. Comparison of expected plasma potential profiles at channel centerline and along the wall, based on the assumption that magnetic field lines are equipotentials. The acceleration zone near the wall moves downstream and contains larger axial electric fields, creating radial electric fields away from the walls (plasma lens topology).

If the number density along a field line were highly non-uniform, Eq. 5 shows that equipotentials could deviate strongly from magnetic field lines. Given the large number density differences found between centerline and the wall, coupled with the high electron temperature in this region, it is possible to have potential differences upwards of $70 \mathrm{~V}$ along a magnetic field line. Therefore, the large radial number density gradients could be responsible for the observed trends in plasma potential. These gradients cause the deviation between magnetic field lines and equipotentials to be so strong near the wall that they create "defocusing" electric fields that drive ions towards the channel walls. This defocusing effect near the walls has also been observed by Huang et al. [18] in the H6 Hall thruster using 2-axis laser induced fluorescence (LIF).

\section{B. Asymmetry between Inner and Outer Walls}

It was shown in Section III that, despite the use of a symmetric magnetic field topology, asymmetry was observed between the channel walls in the plasma potential, electron temperature, and ion number density. In particular, the acceleration zone along the outer channel wall was found to begin slightly upstream of the acceleration zone along the inner wall, and a similar trend was found in the peak electron temperature. If the plasma accelerates further upstream along the outer wall, ions should gain more energy and begin sputtering wall material further upstream as well. Figure 18 compares the measured erosion profiles of the inner and outer channel walls of the H6 Hall thruster after 334 hours of operation. It is evident that more erosion is present along the outer wall, and the erosion also begins further upstream compared to the inner wall. This is consistent with the measured plasma potential profiles, as ions will have higher energy at each axial location along the outer wall and therefore create a higher erosion rate. 


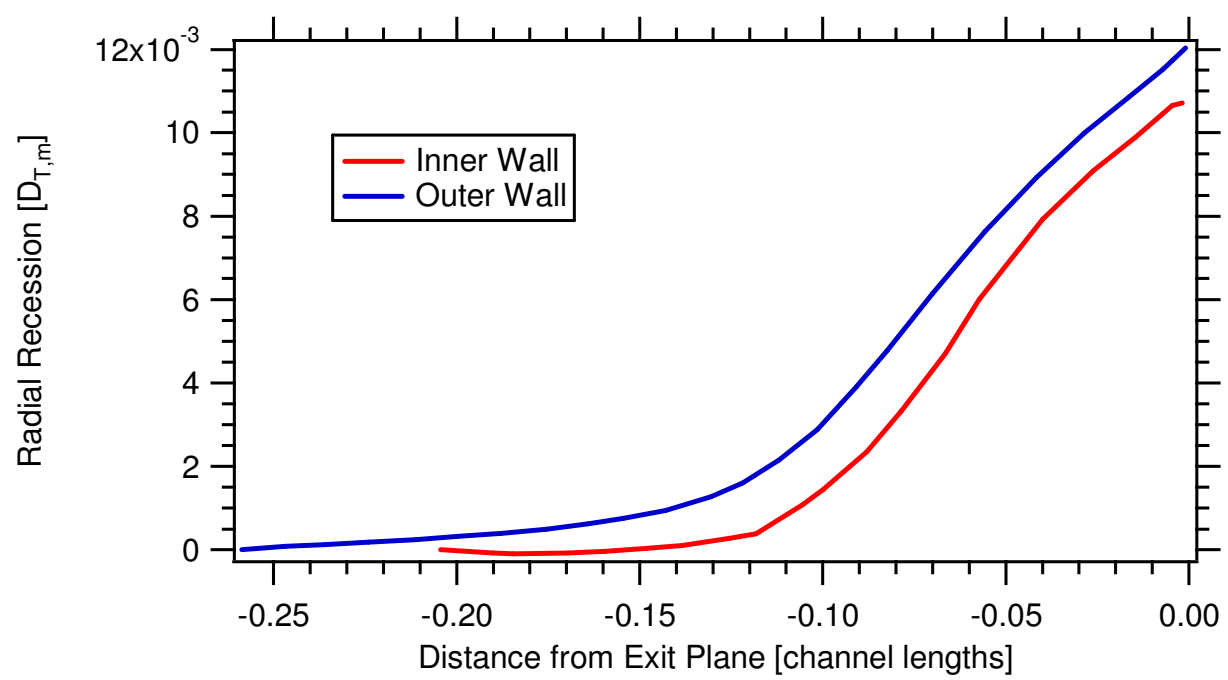

Figure 18. Comparison of measured erosion profiles between inner and outer channel walls of the H6 Hall thruster after 334 hours of operation. Increased erosion is observed along the outer wall, consistent with measurements of plasma potential in this study.

Further insight into the source of this asymmetry can be found by looking at the profiles of radial magnetic field along each channel wall. Figure 19 shows the simulated profiles of radial magnetic field along each wall using the program MagNet. It is evident that the location of the peak magnetic field along the outer wall is upstream of the peak along the inner wall. The radial magnetic field strength strongly influences the location of the acceleration zone; stronger radial magnetic fields result in increased electrical resistivity du $\mathrm{e}$ to the electrons being more strongly magnetized. From Ohm's law, this increased resistivity results in a higher electric field to enforce current continuity throughout the circuit. Thus, the axial shift in peak magnetic field is consistent with the observed axial shift in acceleration zones between inner and outer walls. Furthermore, since the electrons gain their energy through the axial electric field, this shift is also consistent with the axial profiles of electron temperature. It is worth noting that, even though these asymmetries are observable, the axial shift is only $\sim 0.02$ channel lengths; therefore, the profiles are not highly asymmetric.

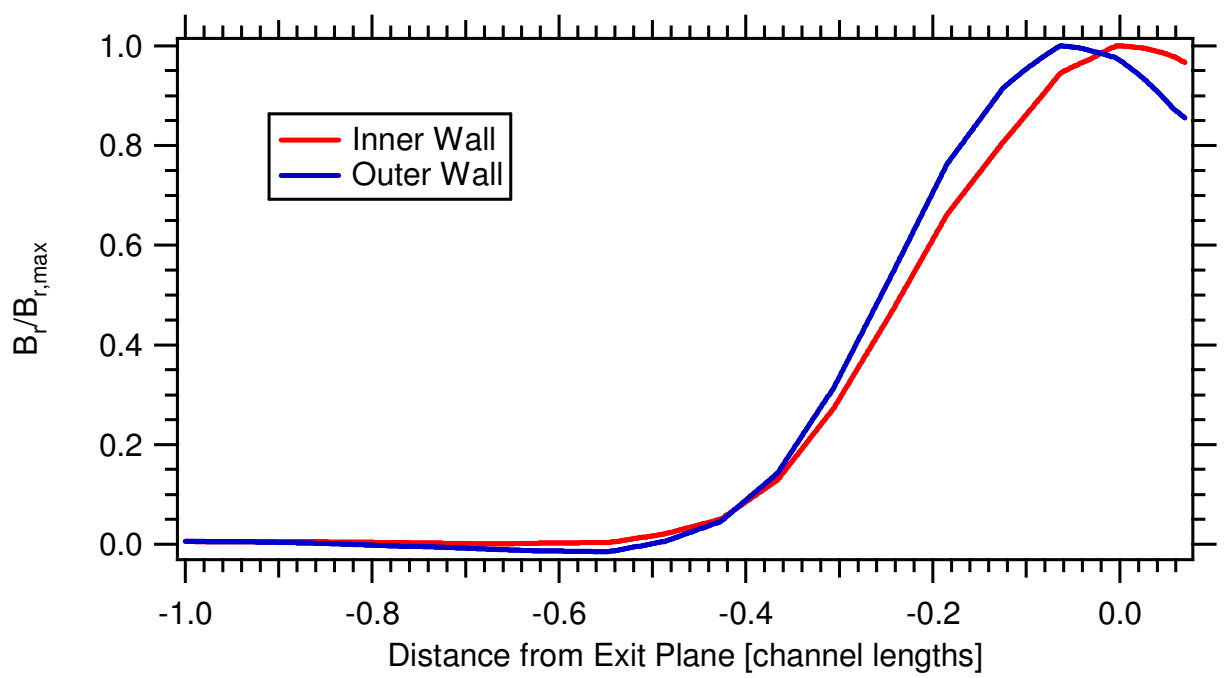

Figure 19. Comparison of the simulated profiles of radial magnetic field along the inner and outer walls of the H6 Hall thruster. The peak magnetic field along the inner wall occurs downstream of the peak along the outer wall, consistent with plasma potential measurements. 


\section{Comparisons with HPHall-2 Simulations}

The axial profiles presented in Section III are now compared to computational results generated by HPHall-2. HPHall-2 is a two-dimensional hybrid-particle-in-cell (PIC) code in cylindrical r-z geometry that simulates the performance and plasma characteristics of a Hall thruster under various geometries and operating conditions. Details about the original HPHall can be found in Ref. [42], while details of the updates to HPHall-2 by Parra and the modifications made by the Jet Propulsion Laboratory (JPL) can be found in Refs. [1,43-45]. The version used in this study is the JPL-modified HPHall-2 described in Ref. [1]. The grid geometry of the H6 Hall thruster was modified to include the chamfers present in the erosion rings of this study. Table 2 shows the measured and simulated values of performance for the H6 Hall thruster at nominal conditions of $300 \mathrm{~V}$ and $20 \mathrm{mg} / \mathrm{s}$ anode flow rate, showing excellent agreement between the two.

Table 2. Comparison of measured and simulated performance values for the H6 Hall thruster at nominal conditions.

\begin{tabular}{ccc} 
Discharge Property & Measured Value & Simulated Value \\
\hline Discharge Voltage [V] & 300 & 300 \\
Anode Flow Rate [mg/s] & 20 & 20 \\
Discharge Current [A] & 20.1 & 20.1 \\
Thrust [mN] & 385 & 388 \\
Anode Efficiency & 0.614 & 0.624
\end{tabular}

A comparison of simulated and measured axial profiles of plasma potential at $300 \mathrm{~V}, 20 \mathrm{mg} / \mathrm{s}$ anode flow rate is shown in Figure 20. All profiles show the acceleration zone contained within the last $10 \%$ of the channel, and the maximum axial electric fields are also consistently around 50-60 V/mm. Furthermore, the HPHall-2 results indicate the plasma near the walls accelerating further upstream than the plasma at centerline. This is more easily seen in the plasma potential contour map shown in Figure 21. Equipotential lines are nearly radial in the vicinity of the exit plane; however, about 0.1 channel widths from the wall the lines curves upstream, creating the defocusing fields observed in the experimental data. These fields tend to bend the ion trajectories towards the wall, which will affect overall ion power deposition to the walls as well as the local wall erosion rates.

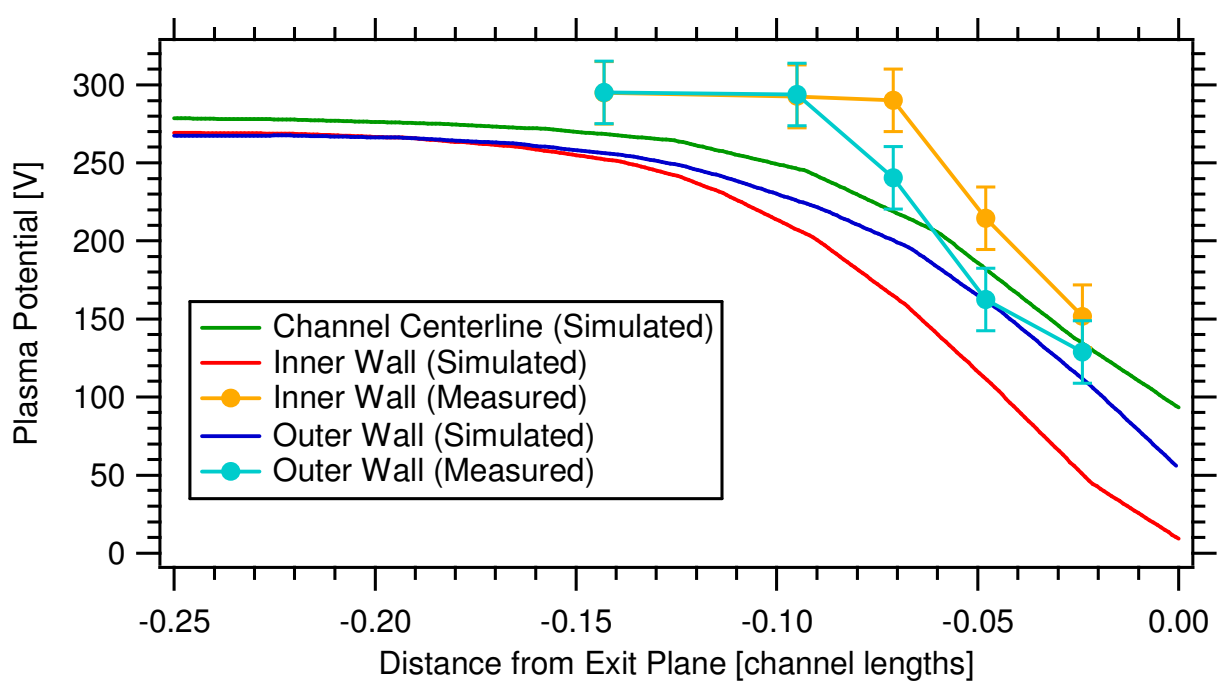

Figure 20. Comparison of simulated and measured axial profiles of plasma potential at $300 \mathrm{~V}, 20 \mathrm{mg} / \mathrm{s}$ anode flow rate. The acceleration zone location is consistent between the two, but the simulation indicates a $30 \mathrm{~V}$ drop from anode potential upstream of the acceleration zone that is not present in the experimental data. 


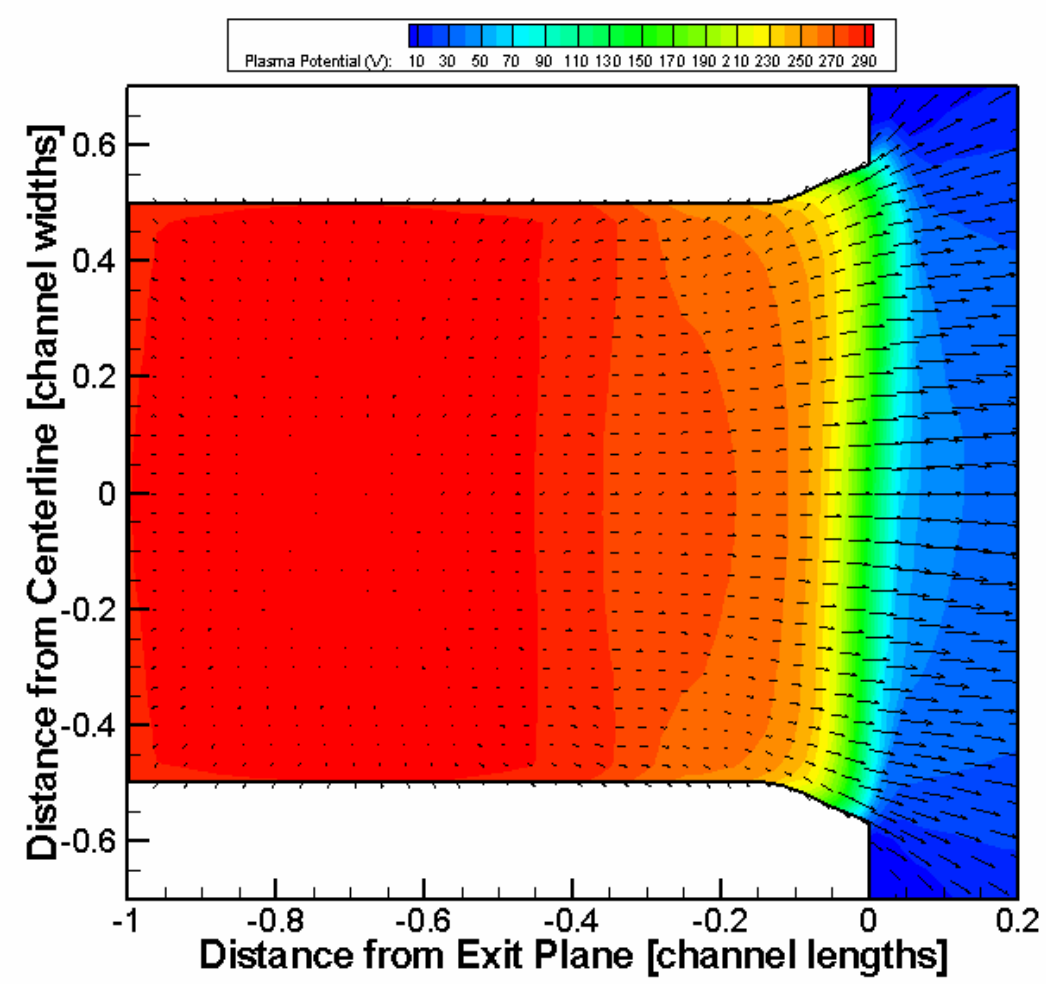

Figure 21. Simulated plasma potential contours from HPHall-2 at $300 \mathrm{~V}$ and $20 \mathrm{mg} / \mathrm{s}$ anode flow rate. Ion velocity vectors have been overlaid to emphasize particle motion. Defocusing fields are present close to the channel walls that drive ions away from centerline, consistent with measurements in this study.

While the acceleration zone locations are consistent between simulation and experiment, there is a $30 \mathrm{~V}$ drop in plasma potential upstream of the acceleration zone in the HPHall-2 results that is not present in the measurements. This is due to the importance of ion diffusion far upstream of the acceleration zone that is not captured in HPHall-2 since ions are modeled using particle-in-cell methods [1]. The two-dimensional code Hall 2De, which models the ions as a fluid, has been shown to eliminate this potential drop in Hall thruster simulations [3]. Lastly, it is interesting to note that while the HPHall-2 results also show asymmetry between the inner and outer walls, the trend is reversed from what is found in the measurements (i.e. plasma is accelerated further upstream along the inner wall compared to the outer wall). The source of this discrepancy is unclear at this time; however, based on the discussion in Section IV-B, the experimental results likely show the correct trend.

Figure 22 compares simulated and measured axial profiles of electron temperature at $300 \mathrm{~V}$ and $20 \mathrm{mg} / \mathrm{s}$ anode flow rate. The maximum electron temperature of $35 \mathrm{eV}$ is consistent across all radial locations and between HPHall-2 and experimental results. The location of the maximum electron temperature, however, occurs further upstream in the experiment compared to the simulation. The discrepancy was found to occur along channel centerline as well, by approximately $5 \%$ of the channel length. This result is unexpected due to the excellent agreement in plasma potential profiles and acceleration zone location between simulation and experiment. Furthermore, the shift in peak location between inner and outer walls is also reversed in the simulation compared to experiment. Since this shift occurs over only $2 \%$ of the channel length, it is not highly significant. This reversal, however, is consistent with the observed shifts in acceleration zone. 


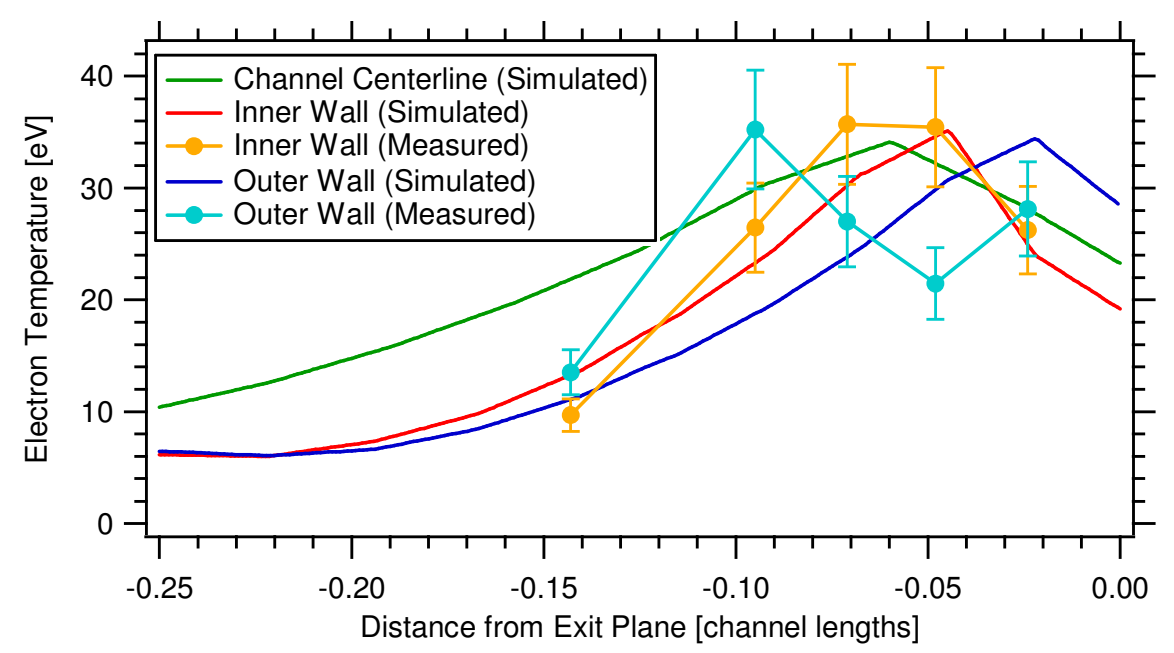

Figure 22. Comparison of simulated and measured axial profiles of electron temperature at $300 \mathrm{~V}, 20 \mathrm{mg} / \mathrm{s}$ anode flow rate. While the peak electron temperature is consistent between the two, the location of the peak along the outer wall is further upstream in the simulation than measured.

Figure 23 compares the simulated and measured axial profiles of ion number density at $300 \mathrm{~V}$ and $20 \mathrm{mg} / \mathrm{s}$ anode flow rate. The ion number density calculated from the "Beam" method described in Section III-D was used for the experimental results, while the sum of the singly-ionized and doubly-ionized xenon densities was used for the simulation results. It is evident from the figure that HPHall-2 consistently underpredicts the ion density at all locations; this was found to be true at channel centerline as well. However, the simulation reproduces the reduced ion densities at the wall compared to channel centerline, with peak values differing by a factor of 4 (inner wall) to six (outer wall). This difference could be responsible for the formation of defocusing fields in the vicinity of the walls, as previously discussed in Section IV-A. Due to limited axial extent of the experimental data, it is unclear if the peak location between simulation and measurement is consistent; however, the monotonic decrease in number density observed in experiment is reproduced in the HPHall-2 results.

The large discrepancy between simulation and experiment upstream of the acceleration zone could be due to the non-uniform plasma potential between the walls and channel centerline present in the HPHall-2 results. Using the Boltzmann relation (Eq. 5) and an electron temperature of $10 \mathrm{eV}$, this $10 \mathrm{~V}$ drop creates a $2.7 \mathrm{X}$ drop in plasma density between channel centerline and the walls. This illustrates the sensitivity of ion number density to small differences in plasma potential. Given this sensitivity and the $\pm 60 \%$ uncertainty in the measured ion number density, the simulation and experimental results are in reasonable agreement with one another.

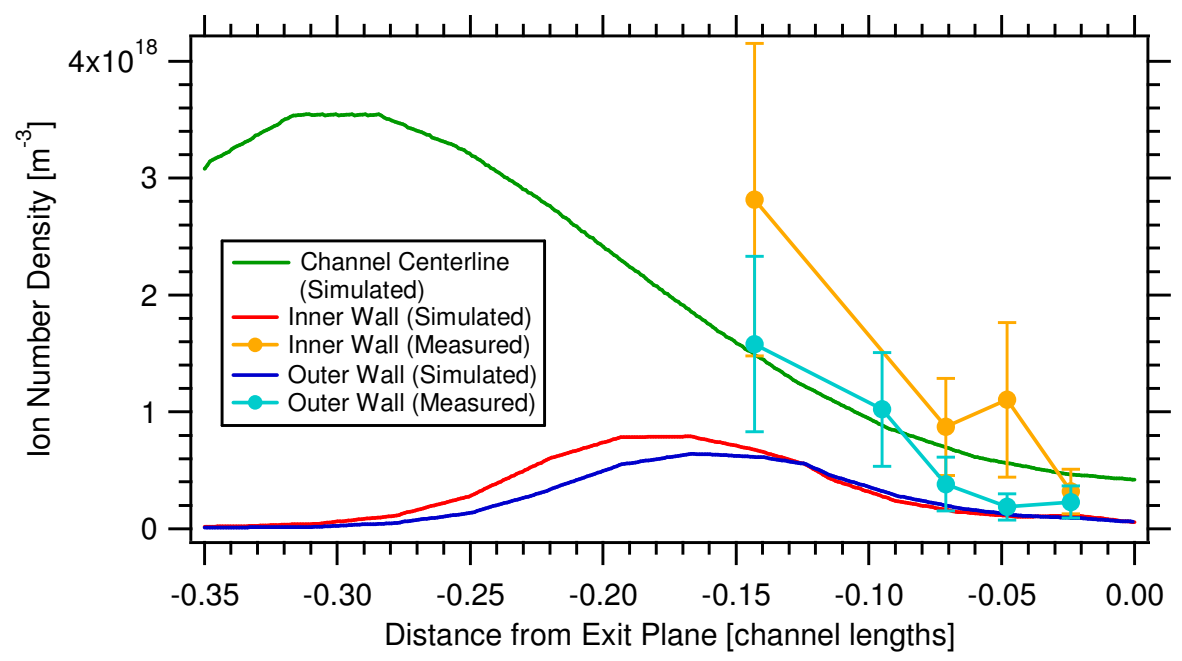

Figure 23. Comparison of simulated and measured axial profiles of ion number density at $300 \mathrm{~V}, 20 \mathrm{mg} / \mathrm{s}$ anode flow rate. Measured values are consistently higher than simulated values. It is unclear whether the peak location in the simulation matches experiment due to lack of data. 


\section{Conclusions}

Five Langmuir probes were flush-mounted into each erosion ring of the H6 Hall thruster in order to characterize the near-wall plasma and compare its properties to those closer to channel centerline. Comparison of plasma potential profiles at nominal conditions shows that the plasma near the wall begins to accelerate further upstream than plasma at centerline, creating large radial electric fields that drive ions towards the wall. This "defocusing" effect was found to be caused by large number density gradients between channel centerline and the walls. The maximum electron temperature was found to be consistent across the radial extent of the channel. This peak temperature occurred at roughly the same axial location, validating the isothermal assumption along magnetic field lines since they are nearly radial in the experimental interrogation zone. Simulation results from HPHall-2 were found to generally agree with experimental results near the wall, with only minor differences in peak locations. Asymmetries in plasma properties observed between the inner and outer channel wall were created by a small difference in peak radial magnetic field location, causing a slight shift in acceleration zone and peak electron temperature location. This resulted in slightly asymmetric erosion profiles between the channel walls, with more erosion occurring along the outer wall. This experimental characterization should further illuminate the interactions between the plasma and channel walls within Hall thrusters. Understanding of these interactions is critical towards improving efficiency (by reducing wall losses) as well as extending thruster lifetime.

\section{Acknowledgments}

The authors would like to thank and acknowledge Wensheng Huang and Michael McDonald for their assistance during the experiment, Ray Liang for his assistance during the experiment as well as performing the magnetic field simulation referred to in this study, and Ira Katz for fruitful discussion as well as aiding in development of the sheath expansion model used in the study. The authors would also like to thank and acknowledge the Air Force Office of Scientific Research (AFOSR) for funding the experiments in this study. Dr. Mitat Birkan is the project manager for Grant FA9550-06-1-0105. The lead author was supported under the Graduate Student Research Program through the National Aeronautics and Space Administration.

Portions of this research were carried out at the Jet Propulsion Laboratory, California Institute of Technology, under a contract with the National Aeronautics and Space Administration.

\section{References}

[1] Hofer, R. R., Katz, I., Mikellides, I. G., Goebel, D. M., Jameson, K. K. et al., "Efficacy of Electron Mobility Models in Hybrid-PIC Hall Thruster Simulations," Presented at the 44th AIAA/ASME/SAE/ASEE Joint Propulsion Conference and Exhibit, AIAA-2008-4924, Hartford, CT, July 20-23, 2008.

[2] Hofer, R. R., Mikellides, I. G., Katz, I., and Goebel, D. M., "BPT-4000 Hall Thruster Discharge Chamber Erosion Model Comparison with Qualification Life Test Data," Presented at the 30th International Electric Propulsion Conference, IEPC-2007-267, Florence, Italy, September 17-20, 2007.

[3] Mikellides, I. G., Katz, I., Hofer, R. R., and Goebel, D. M., "Hall-effect Thruster Simulations with 2-D Electron Transport and Hydrodynamic Ions," Presented at the 31st International Electric Propulsion Conference, IEPC-2009114, Ann Arbor, MI, September 20 - 24, 2009.

[4] Mikellides, I. G., Katz, I., Hofer, R. R., Goebel, D. M., De Grys, K. et al., "Magnetic Shielding of the Acceleration Channel in a Long-Life Hall Thruster," Physics of Plasmas 18, 033501 (2011).

[5] Yim, J. T., Keidar, M., and Boyd, I. D., "A Hydrodynamic-Based Erosion Model for Hall Thrusters," Presented at the 29th International Electric Propulsion Conference, IEPC-2005-013, Princeton, NJ, October 31 - November 4, 2005.

[6] Ahedo, E. and Parra, F. I., "Partial trapping of secondary-electron emission in a Hall thruster plasma," Physics of Plasmas 12, 7, 073503-1 - 073503-7 (2005).

[7] Barral, S., Makowski, K., Peradzynski, Z., Gascon, N., and Dudeck, M., "Wall material effects in stationary plasma thrusters. II. Near-wall and in-wall conductivity," Physics of Plasmas 10, 10, 4137-4152 (2003).

[8] Keidar, M., Boyd, I. D., and Beilis, I. I., "Plasma flow and plasma-wall transition in Hall thruster channel," Physics of Plasmas 8, 12, 5315-5322 (2001).

[9] Azziz, Y., Warner, N. Z., Martinez-Sanchez, M., and Szabo, J. J., "High Voltage Plume Measurements and Internal Probing of the BHT-1000 Hall Thruster," Presented at the 40th AIAA/ASME/SAE/ASEE Joint Propulsion Conference and Exhibit, AIAA-2004-4097, Fort Lauderdale, FL, July 11-14, 2004.

[10] Kim, V., Grdlichko, D., Kozlov, V., Lazourenko, A., Popov, G. et al., "Local Plasma Parameter Measurements by Nearwall Probes Inside the SPT Accelerating Channel Under Thruster Operation with Kr," Presented at the 38th AIAA/ASME/SAE/ASEE Joint Propulsion Conference and Exhibit, AIAA-2002-4108, Indianapolis, IN, July 7-10, 2002. 
[11] Kim, V., Kozlov, V., Skrylnikov, A., Umnitsin, L. N., Svotina, V. V. et al., "Investigation of the Local Plasma Parameters in the SPT Accelerating Channel Under Increased Discharge Voltages," Presented at the 29th International Electric Propulsion Conference, IEPC-2005-004, Princeton, NJ, October 31 - November 4, 2005.

[12] Szabo, J. J., Warner, N. Z., and Martinez-Sanchez, M., "Instrumentation and Modeling of a High Isp Hall Thruster," Presented at the 38th AIAA/ASME/SAE/ASEE Joint Propulsion Conference and Exhibit, AIAA-2002-4248, Indianapolis, IN, July 7-10, 2002.

[13] Haas, J. M., "Low-Perturbation Interrogation of the Internal and Near-Field Plasma Structure of a Hall Thruster Using a High-Speed Probe Positioning System," Ph.D. Dissertation, Aerospace Engineering, University of Michigan, 2001.

[14] Linnell, J. A., "An Evaluation of Krypton Propellant in Hall Thrusters," Ph.D. Dissertation, Aerospace Engineering, University of Michigan, 2007.

[15] Reid, B. M., "The Influence of Neutral Flow Rate in the Operation of Hall Thrusters," Ph.D. Dissertation, Aerospace Engineering, University of Michigan, 2008.

[16] Hargus, W. A., Nakles, M. R., Tedrake, R., and Pote, B., "Effect of Anode Current Fluctuations on Ion Energy Distributions within a $600 \mathrm{~W}$ Hall Effect Thruster," Presented at the 44th AIAA/ASME/SAE/ASEE Joint Propulsion Conference and Exhibit, AIAA-2008-4724, Hartford, CT, July 21 - 23, 2008.

[17] Huang, W., Drenkow, B., and Gallimore, A. D., "Laser-Induced Fluorescence of Singly-Charged Xenon inside a 6-kW Hall Thruster," Presented at the 45th AIAA/ASME/SAE/ASEE Joint Propulsion Conference and Exhibit, AIAA-20095355, Denver, CO, August 2 - 5, 2009.

[18] Huang, W., Gallimore, A., and Smith, T. B., "Two-Axis Laser-Induced Fluorescence of Singly-Charged Xenon inside a 6-kW Hall Thruster," Presented at the 49th AIAA Aerospace Sciences Meeting, AIAA-2011-1015, Orlando, FL, Jan. 4 $-7,2011$.

[19] Kim, V., Kozlov, V., Skrylnikov, A., Sidorenko, E. K., Murashko, V. M. et al., "Investigation of the SPT operation and discharge chamber wall erosion rate under increased discharge voltages," Presented at the 30th International Electric Propulsion Conference, IEPC-2007-151, Florence, Italy, September 17-20, 2007.

[20] Shastry, R., Gallimore, A. D., and Hofer, R. R., "Near-Wall Plasma Characterization of a 6-kW Hall Thruster," Presented at the 31st International Electric Propulsion Conference, IEPC-2009-133, Ann Arbor, MI, September 20 - 24, 2009.

[21] Shastry, R., Gallimore, A. D., and Hofer, R. R., "Erosion Characterization via Ion Power Deposition Measurements in a 6-kW Hall Thruster," Presented at the 57th JANNAF Propulsion Meeting, JANNAF-2010-1205, Colorado Springs, CO, May 3 - 7, 2010.

[22] Brown, D. L., "Investigation of Low Discharge Voltage Hall Thruster Characteristics and Evaluation of Loss Mechanisms," Ph.D. Dissertation, Aerospace Engineering, The University of Michigan, 2009.

[23] Brown, D. L., Reid, B. M., Gallimore, A. D., Hofer, R. R., Haas, J. M. et al., "Performance Characterization and Design Verification of the H6 Laboratory Model Hall Thruster," Presented at the 54th JANNAF Propulsion Meeting, Denver, CO, 14-17 May, 2007.

[24] Haas, J. M., Hofer, R. R., Brown, D. L., Reid, B. M., and Gallimore, A. D., "Design of the H6 Hall Thruster for High Thrust/Power Investigation," Presented at the 54th JANNAF Propulsion Meeting, Denver, CO, 14-17 May, 2007.

[25] Jameson, K. K., Goebel, D. M., Hofer, R. R., and Watkins, R. M., "Cathode Couplings in Hall Thrusters," Presented at the 30th International Electric Propulsion Conference, IEPC-2007-278, Florence, Italy, September 17-20, 2007.

[26] Mcdonald, M. S. and Gallimore, A. D., "Cathode Position and Orientation Effects on Cathode Coupling in a 6-kW Hall Thruster," Presented at the 55th JANNAF Propulsion Meeting, SPS-III-33, Orlando, FL, December 8-12, 2008.

[27] Reid, B. M. and Gallimore, A., "Near-field Ion Current Density Measurements of a 6-kW Hall Thruster," Presented at the 31st International Electric Propulsion Conference, IEPC-2009-124, Ann Arbor, MI, September 20 - $24,2009$.

[28] Reid, B. M. and Gallimore, A. D., "Langmuir Probe Measurements in the Discharge Channel of a 6-kW Hall Thruster," Presented at the 44th AIAA/ASME/SAE/ASEE Joint Propulsion Conference and Exhibit, AIAA-2008-4920, Hartford, CT, July $21-23,2008$.

[29] Reid, B. M. and Gallimore, A. D., "Plasma Potential Measurements in the Discharge Channel of a 6-kW Hall Thruster," Presented at the 44th AIAA/ASME/SAE/ASEE Joint Propulsion Conference and Exhibit, AIAA-2008-5185, Hartford, CT, July 21 - 23, 2008.

[30] Reid, B. M., Gallimore, A. D., Hofer, R. R., Li, Y., and Haas, J. M., "Anode Design and Verification for the H6 Hall Thruster," Presented at the 54th JANNAF Propulsion Meeting, Denver, CO, 14-17 May, 2007.

[31] Reid, B. M., Shastry, R., Gallimore, A. D., and Hofer, R. R., "Angularly-Resolved ExB Probe Spectra in the Plume of a 6-kW Hall Thruster," Presented at the 44th AIAA/ASME/SAE/ASEE Joint Propulsion Conference and Exhibit, AIAA2008-5287, Hartford, CT, July 21-23, 2008.

[32] Hofer, R. R., Goebel, D. M., and Watkins, R. M., "Compact LaB ${ }_{6}$ Hollow Cathode for the H6 Hall Thruster," Presented at the 54th JANNAF Propulsion Meeting, Denver, CO, 14-17 May, 2007.

[33] Hofer, R. R., Goebel, D. M., Snyder, J. S., and Sandler, I., "BPT-4000 Hall Thruster Extended Power Throttling Range Characterization for NASA Science Missions," Presented at the 31st International Electric Propulsion Conference, IEPC-2009-085, Ann Arbor, MI, September 20 -24, 2009.

[34] Haag, T. W., "Design of a Thrust Stand for High Power Electric Propulsion Devices," Presented at the 25th AIAA/ASME/SAE/ASEE Joint Propulsion Conference, AIAA-1989-2829, Monterey, CA, July 10 -13, 1989. 
[35] Xu, K. G. and Walker, M. L. R., "High-power, null-type, inverted pendulum thrust stand," Review of Scientific Instruments 80, 5, 055103-1 - 055103-6 (2009).

[36] Lobbia, R. B. and Gallimore, A. D., "High-speed dual Langmuir probe," Review of Scientific Instruments 81, 7, 073503-1 - 073503-9 (2010).

[37] Sheridan, T. E., "How big is a small Langmuir probe?," Physics of Plasmas 7, 7, 3084-3088 (2000).

[38] Brophy, J. R., Katz, I., Polk, J. E., and Anderson, J. R., "Numerical Simulations of Ion Thruster Accelerator Grid Erosion," Presented at the 38th AIAA/ASME/SAE/ASEE Joint Propulsion Conference and Exhibit, AIAA-2002-4261, Indianapolis, IN, July 7-10, 2002.

[39] Hobbs, G. D. and Wesson, J. A., "Heat flow through a Langmuir sheath in the presence of electron emission," Plasma Physics 9, 85-87 (1967).

[40] Warner, N. Z., "Performance Testing and Internal Probe Measurements of a High Specific Impulse Hall Thruster," Master's Thesis, Aeronautics and Astronautics, Massachusetts Institute of Technology, 2003.

[41] Lieberman, M. A. and Lichtenberg, A. J., Principles of Plasma Discharges and Materials Processing, Second ed. (John Wiley \& Sons, Inc., Hoboken, NJ, 2005).

[42] Fife, J. M., "Hybrid-PIC Modeling and Electrostatic Probe Survey of Hall Thrusters," Ph.D. Dissertation, Aeronautics and Astronautics, Massachusetts Institute of Technology, 1999.

[43] Hofer, R. R., Katz, I., Mikellides, I. G., and Gamero-Castaño, M., "Heavy Particle Velocity and Electron Mobility Modeling in Hybrid-PIC Hall Thruster Simulations," Presented at the 42nd AIAA/ASME/SAE/ASEE Joint Propulsion Conference and Exhibit, AIAA-2006-4658, Sacramento, CA, July 9-12, 2006.

[44] Hofer, R. R., Mikellides, I. G., Katz, I., and Goebel, D. M., "Wall Sheath and Electron Mobility Modeling in HybridPIC Hall Thruster Simulations," Presented at the 43rd AIAA/ASME/SAE/ASEE Joint Propulsion Conference and Exhibit, AIAA-2007-5267, Cincinnati, OH, July 8-11, 2007.

[45] Parra, F. I., Ahedo, E., Fife, J. M., and Martinez-Sanchez, M., "A two-dimensional hybrid model of the Hall thruster discharge," Journal of Applied Physics 100, 2, 023304-1 - 023304-11 (2006). 